Review Article

\title{
Psychological Therapies in Patients with Irritable Bowel Syndrome: A Systematic Review and Meta-Analysis of Randomized Controlled Trials
}

\author{
Osama Altayar, ${ }^{1}$ Varun Sharma, ${ }^{2}$ Larry J. Prokop, ${ }^{3}$ \\ Amit Sood, ${ }^{2}$ and Mohammad Hassan Murad ${ }^{3}$ \\ ${ }^{1}$ Department of Internal Medicine, Allegheny General Hospital-Western Pennsylvania Hospital Medical Education Consortium, \\ Pittsburgh, PA, USA \\ ${ }^{2}$ Division of General Internal Medicine, Mayo Clinic, Rochester, MN, USA \\ ${ }^{3}$ Center for the Science of Health Care Delivery, Mayo Clinic, Rochester, MN, USA
}

Correspondence should be addressed to Varun Sharma; sharma.varun@mayo.edu

Received 14 October 2014; Accepted 9 December 2014

Academic Editor: Bjørn Moum

Copyright (C) 2015 Osama Altayar et al. This is an open access article distributed under the Creative Commons Attribution License, which permits unrestricted use, distribution, and reproduction in any medium, provided the original work is properly cited.

Background. Irritable bowel syndrome (IBS) is a poorly understood disease with few effective treatments. Psychosocial factors are believed to contribute to the pathogenesis of IBS. Objective. To evaluate the evidence for psychological therapies in IBS treatment. Methods. We searched six medical databases through February 6, 2014, for randomized controlled trials (RCTs) of psychological therapies for the treatment of IBS. Two independent reviewers identified the RCTs, extracted the data, and assessed trial quality. We used the random-effect model to pool standardized mean difference (SMD) and 95\% confidence interval (CI) across trials. Results. 15 RCTs that mostly evaluated cognitive behavioral therapy were included. Psychological therapies were associated with improvement in IBS symptoms severity scales (SMD -0.618; 95\% CI: -0.853 to -0.383), IBS-Quality of Life (SMD 0.604; 95\% CI: 0.440 to 0.768 ), and abdominal pain (SMD $-0.282 ; 95 \%$ CI: -0.562 to -0.001 ). No statistically significant effect was observed on diarrhea or constipation. Limitations. The trials were at increased risk of bias and the overall sample size was small leading to imprecision. Conclusion. Psychological therapies may improve the quality of life and symptom severity in IBS. The effect size noted is moderate to large and is clinically meaningful.

\section{Introduction}

Irritable bowel syndrome (IBS) is a complex and widespread functional bowel disorder (10-20\% worldwide prevalence [1]) that is not well understood. IBS typically presents as persistent diarrhea and/or constipation that is accompanied by abdominal discomfort. The symptoms as well as the underlying etiologies of IBS can vary considerably from patient to patient. Some of these causes may include diet, genetics, altered intestinal environment, and dysregulation of the enteric nervous system function. Multiple treatments targeting these possible causes have been used for several decades but have largely only been demonstrated to temporarily treat symptoms.
Recently, acknowledgment of the role of stress and psychosocial factors in some cases has led to the examination of psychological therapies targeting these factors in the treatment of IBS. In the past few decades, research has uncovered an extensive bidirectional communication network between the brain and the gut termed the braingut axis [2]. This provides a pathophysiologic basis for the potential therapeutic effects of psychological therapies on gut function. This has been further supported by several, small, randomized controlled trials demonstrating the preliminary efficacy of psychological therapies on IBS symptoms [3-7]. Hypnotherapy has been suggested to treat abdominal pain, improve quality of life, and reduce anxiety and depression in IBS without any side effects [8-10]. These effects persisted 
for several years, although definitive conclusions will require larger, higher quality studies. Cognitive behavioral therapies (CBT) and mind-body therapies (MBT) have also been studied in IBS with some studies showing preliminary efficacy [11-13]. Psychological therapies are potentially efficacious in treating IBS symptoms in many patients, and unlike many pharmaceutical treatments, they have minimal side effects and can be cost-effective [14-17].

To examine if psychological therapies merit incorporation in the clinical treatment of IBS, we conducted this systematic review and meta-analysis of published randomized controlled trials. To our knowledge, no existing systematic reviews with meta-analysis have addressed this question.

\section{Methods}

Investigators developed a protocol in advance to specify eligibility criteria, outcomes of interest, and analysis methods. The methodology and reporting of this systematic review comply with the Preferred Reporting Items for Systematic Reviews and Meta-Analyses (PRISMA statement) [18].

2.1. Eligibility Criteria. We included randomized controlled trials that enrolled patients of unspecified gender and aged at least 18 years. Subjects of the included trials were diagnosed with irritable bowel syndrome (IBS) based on one of the following criteria: Latimer criteria, Manning criteria, Kruis criteria, Rome I criteria, Rome II criteria, Rome III criteria, or clinician defined diagnosis $[12,15,17,19-38]$. We included trials that evaluated the efficacy of psychological interventions, including cognitive-behavioral therapies, mind-body therapies, and other psychological interventions, compared to no intervention, waiting list, placebo, diet, herbal treatment, or symptomatic management. Only trials that evaluated the efficacy of psychological interventions using composite IBS symptoms severity scales, individual IBS symptoms severity scales, or quality of life scales were included.

Nonrandomized comparative studies and single arm studies were not included. We excluded trials that evaluated hypnotherapy because multiple systematic reviews have already summarized this evidence [8-10]. We also excluded non-English references.

2.2. Search Methods. A comprehensive search of several databases from 1966 to February 6, 2014, any language, was conducted. The databases included Ovid Medline In-Process \& Other Non-Indexed Citations, Ovid MEDLINE, Ovid EMBASE, Ovid PsycINFO, Ovid Cochrane Central Register of Controlled Trials, Ovid Cochrane Database of Systematic Reviews, and Scopus. The search strategy was designed and conducted by an experienced librarian with input from the study's principal investigator. Controlled vocabulary supplemented with keywords was used to search for comparative studies of psychological and mind-body interventions for irritable bowel syndrome. The actual strategy is included in the Appendix.

2.3. Study Selection. Two independent blinded reviewers (OA and VS) assessed the eligibility of the candidate references for inclusion by screening titles and abstracts initially. The full-text publications were then retrieved and their eligibility was assessed. Disagreement between the two reviewers was resolved by meeting and establishing consensus. Interreviewer agreement was measured by using the Kappa statistic.

2.4. Data Collection Process. Data were abstracted from each study using a standardized and piloted Microsoft Excel spreadsheet-based extraction form. Two independent blinded reviewers (OA and VS) did the abstraction in duplicate and disagreements were resolved by meeting and establishing consensus. The following data were abstracted: description of enrolled patients (inclusion criteria, age, gender, race, and previous treatment), description of received interventions and control, follow-up monitoring, and measures of outcome.

2.5. Outcomes of Interest. The primary outcomes were the composite IBS symptoms severity scales and quality of life. Other outcomes were diarrhea, constipation, and abdominal pain.

2.6. Assessment of the Risk of Bias. Two reviewers (OA and VS) evaluated the methodological quality of the included trials. To evaluate randomized controlled trials, we used the Cochrane Risk of Bias tool [39]. We evaluated the adequacy of randomization, allocation concealment, blinding (patients, providers, data collectors, and outcome assessors), baseline imbalance, and extent of loss to follow-up. We also extracted the funding source.

2.7. Statistical Analysis. Because the outcomes of interest were evaluated in the included trials using different scales, we estimated the standardized difference in means (SMD) to measure the difference between the intervention and control groups. SMD calculation involves standardizing the effect and expressing it in standard deviation units, to allow pooling it across trials. For each trial, we calculated the change in the studied scales before and after the intervention and compared it to the change in the control group. Then DerSimonian and Laird random-effects model was used to pool SMD across trials [40].

Inconsistency across the trials was assessed using the $I^{2}$ static and Cochran's $Q$ test. $I^{2}$ value more than $50 \%$ was considered indicative of substantial heterogeneity that is due to real differences in protocols, trial populations, interventions, and/or outcomes. Also, Cochran's $Q$ test $P$ value less than 0.05 indicates that the heterogeneity is beyond chance or random error [41]. We planned to conduct formal tests to assess potential publication bias using visual inspection of funnel plots and Egger's regression asymmetry tests but this was not possible due to the small number of trials [42].

We planned to explore possible causes of heterogeneity by conducting subgroup analyses comparing the effect size between trials that evaluated CBT versus other forms of psychotherapy, trials in which patients received prior treatment versus those who did not, trials with high risk of bias versus low risk of bias, trials in which placebo or sham therapy was 


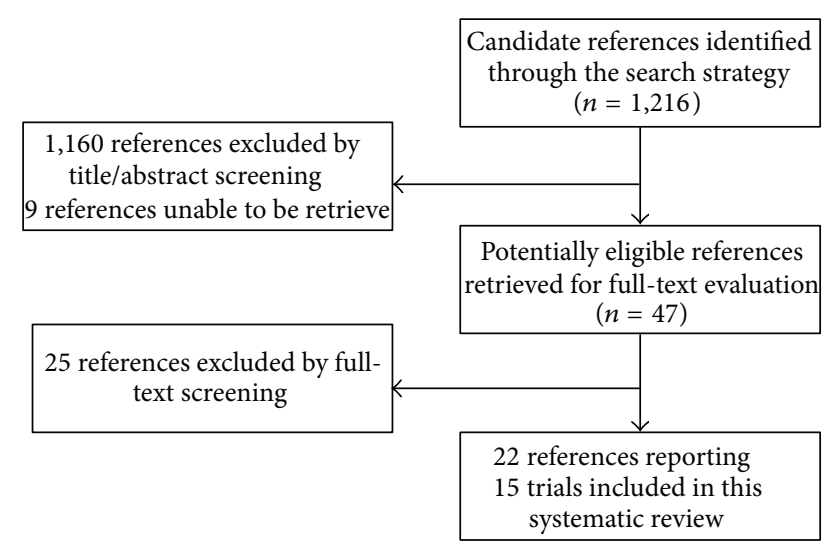

FIGURE 1: Summary of selection process.

used in the control arm, and trials in which the control arm received pharmacological treatment versus those that did not. Interaction test between subgroups was done as suggested by Altman and Bland [43].

Statistical analyses were conducted using Comprehensive Meta-Analysis Version 2.2 [44].

\section{Results}

3.1. Study Selection. A total of 1,216 references were identified through the search strategy. Screening of titles and abstracts excluded 1,160 references (Figure 1). Two reviewers performed the initial screening and had an interreviewer agreement of Kappa of 0.84 . Reviewing the retrieved full texts by the two reviewers excluded 25 publications and the interreviewer agreement about study eligibility, Kappa static, was 0.87 . The remaining 22 publications included 15 trials.

3.2. Study Characteristics. The 15 included RCTs enrolled 1,352 patients. The follow-up period ranged from 10 weeks to 15 months. The criteria for the included patients, baseline characteristics of the included patients, and the interventions they received are detailed in Table 2.

Greene used the Latimer criteria [38] to diagnose IBS while Fernandez used the Manning criteria [45]. Seven of the fifteen trials used Rome I criteria [46] and five trials used the Rome II criteria [47]. Corney et al. used author specified criteria [22].

The included trials evaluated multiple psychological interventions: cognitive-behavioral therapies, psychoeducational courses, mind-body therapy, psychodynamic interpersonal therapy, and contingency management $[12,15,17,19-$ 37].

These interventions were compared to treatment as usual and routine clinical care, providing reading material, attention control, symptom and stressful event monitoring, waiting lists, support groups, standard medical therapy, or placebo $[12,15,17,19-37]$.

The mean age of the included patients ranged from 34 to 50 years. The majority of patients $(1,067 / 1,352)$ were females. Five of the included trials reported previous treatment. Four of them asked the patients to continue the current treatment and the fifth study had the patients go through a 2-week washout period $[12,15,17,19-37]$.

3.3. Risk of Bias within Trials. All the included trials were randomized controlled trials. Assessment of risk of bias for each of the included trials is summarized in Table 1 . Nine of the fifteen trials had high risk of bias. All these nine trials did not provide details about allocation concealment. Seven of them did not report the randomization method. For the remaining two trials, one of them did not report the presence of baseline imbalances and blinding, and the other one had inadequate randomization.

Five of the fifteen included trials had moderate risk of bias. Two of the five had high loss to follow-up rate $(44.5 \%$ and $50.5 \%$ ). The remaining three trials did not report whether allocation was concealed or not. Only one of the fifteen trials was found to have a low risk of bias.

Thirteen of the included trials were funded by a notfor-profit organization. One study did not disclose funding source and one study was funded partially by a pharmaceutical company.

3.4. Meta-Analysis. Nine of the included trials reported change in composite IBS symptoms severity scales. Four of these trials used the Irritable Bowel Syndrome-Severity Scoring System (IBS-SSS) used by Francis et al. [48], three used the Composite Primary Symptoms Reduction (CPSR) score used by Blanchard and Schwarz [49], one used the composite Bowel Symptom Severity (BSS) score used by Spiegel et al. [50], and one used a Global GI Symptoms Severity Score [30]. Random-effects meta-analysis (Figure 2) showed a statistically significant change in composite IBS severity scales in patients who received psychological therapy $(n=383)$ compared to patients receiving control $(n=$ 297 ) with SMD $=-0.618$ SD favoring psychological therapy (95\% CI from -0.853 to -0.383$)$. Moderate heterogeneity was observed $\left(I^{2}=48.04 \%\right.$ and $\left.P=0.052\right)$.

Eight of the included trials reported change in quality of life scales. Three of the included trials used the Irritable Bowel Syndrome-Quality of Life (IBS-QOL) scale used by Drossman et al. [51, 52], two trials used the Physical Component Score of the Short Form 36 Health Survey [53], one study used the Irritable Bowel Syndrome-Quality of Life scale used by Hahn et al. [54], one study used the GI Qualityof-Life Index used by Eypasch et al. [55], and one study used the Work and Social Adjustment Scale used by Mundt et al. [56]. Random-effects meta-analysis (Figure 3) showed a statistically significant change in quality of life scales in patients receiving psychological therapy $(n=352)$ compared to patients receiving control $(n=286)$ with $\mathrm{SMD}=0.604 \mathrm{SD}$ favoring psychological therapy (95\% CI from 0.440 to 0.768 ). No evidence of heterogeneity was observed $\left(I^{2}=0.000 \%\right.$ and $P=0.512$ ).

Eight trials reported change in abdominal pain scales (Figure 4 ). There was a statistically significant change favoring psychological therapy $(n=321)$ compared to control $(n=271)$ on random-effects meta-analysis with 
TABLE 1: Risk of bias assessment in the included trials.

\begin{tabular}{|c|c|c|c|c|c|c|}
\hline $\begin{array}{l}\text { Author, year } \\
\text { (reference) }\end{array}$ & $\begin{array}{c}\text { Randomization } \\
\text { method }\end{array}$ & $\begin{array}{c}\text { Allocation } \\
\text { concealment }\end{array}$ & Blinding & Baseline imbalance & $\begin{array}{l}\text { Lost to } \\
\text { follow-up }\end{array}$ & Source of funding \\
\hline $\begin{array}{l}\text { Corney et al., } 1991 \\
{[22]}\end{array}$ & NR & Unclear & NR & $\begin{array}{c}\text { No significant } \\
\text { differences }\end{array}$ & $2.38 \%$ & NR \\
\hline $\begin{array}{l}\text { Greene and } \\
\text { Blanchard, } 1994 \text { [25] }\end{array}$ & NR & NR & NR & $\begin{array}{l}\text { Matched subjects (GI } \\
\text { symptoms, axis I } \\
\text { psychiatric diagnosis, } \\
\text { sex, duration of IBS, } \\
\text { and age) }\end{array}$ & $7.14 \%$ & NFP \\
\hline $\begin{array}{l}\text { Fernandez et al., } 1998 \\
{[24]}\end{array}$ & NR & NR & NR & $\begin{array}{c}\text { No significant } \\
\text { difference }\end{array}$ & $29.54 \%$ & NFP \\
\hline $\begin{array}{l}\text { Vollmer and } \\
\text { Blanchard, } 1998 \text { [36] }\end{array}$ & NR & NR & NR & $\begin{array}{c}\text { Matched subjects } \\
\text { (DSM-IV axis I } \\
\text { psychiatric diagnosis, } \\
\text { IBS subtypes, age, and } \\
\text { duration of IBS } \\
\text { symptoms) }\end{array}$ & NR & NFP \\
\hline $\begin{array}{l}\text { Heymann-Mönnikes } \\
\text { et al., } 2000 \text { [26] }\end{array}$ & Unclear & Unclear & NR & NR & $7.7 \%$ & NFP \\
\hline Boyce et al., 2003 [20] & $\begin{array}{c}\text { Adequate } \\
\text { Random number } \\
\text { generator }\end{array}$ & $\begin{array}{l}\text { Sealed opaque } \\
\text { envelopes }\end{array}$ & $\begin{array}{l}\text { RCC provider } \\
\text { and data } \\
\text { collector } \\
\end{array}$ & $\begin{array}{l}\text { Participants were } \\
\text { similar }\end{array}$ & $50.48 \%$ & NFP \\
\hline $\begin{array}{l}\text { Creed et al., 2003; } \\
\text { Hyphantis et al., } \\
2009[15,27]\end{array}$ & $\begin{array}{c}\text { Adequate } \\
\text { Computer- } \\
\text { generated } \\
\text { random numbers } \\
\text { Stratified by } \\
\text { hospital and by } \\
\text { pain severity } \\
\end{array}$ & Unclear & Assessors & $\begin{array}{c}\text { No difference in } \\
\text { demographic or } \\
\text { diagnostic variables }\end{array}$ & $13.62 \%$ & NFP \\
\hline $\begin{array}{l}\text { Tkachuk et al., } 2003 \\
\text { [35] }\end{array}$ & NR & NR & NR & $\begin{array}{l}\text { Matched subjects } \\
\text { (DSM axis I disorder, } \\
\text { IBS subtype, IBS } \\
\text { symptom duration, } \\
\text { age, and gender) }\end{array}$ & NR & NFP \\
\hline $\begin{array}{l}\text { McCrone et al., 2008; } \\
\text { Kennedy et al., 2005; } \\
\text { Kennedy et al., } 2006 \\
{[17,28,29]}\end{array}$ & $\begin{array}{c}\text { Adequate } \\
\text { Random number } \\
\text { tables }\end{array}$ & Unclear & NR & $\begin{array}{l}\text { No significant } \\
\text { difference }\end{array}$ & $11.41 \%$ & NFP \\
\hline $\begin{array}{l}\text { Blanchard et al., 2007; } \\
\text { Lackner et al., } 2007 \\
{[19,32]}\end{array}$ & Unclear & Not reported & Not reported & $\begin{array}{l}\text { No between-group } \\
\text { differences at baseline }\end{array}$ & $10.48 \%$ & NFP \\
\hline $\begin{array}{l}\text { Lackner et al., 2010; } \\
\text { Lackner et al., } 2008 \\
{[31,33]}\end{array}$ & $\begin{array}{c}\text { Adequate } \\
\text { Computer- } \\
\text { generated } \\
\text { random numbers }\end{array}$ & Unclear & NR & NR & $16 \%$ & NFP \\
\hline $\begin{array}{l}\text { Chilcot and } \\
\text { Moss-Morris, 2013; } \\
\text { Moss-Morris et al., } \\
2010[21,34]\end{array}$ & $\begin{array}{c}\text { Adequate } \\
\text { Computer- } \\
\text { generated } \\
\text { random numbers }\end{array}$ & $\begin{array}{l}\text { Sealed opaque } \\
\text { envelops }\end{array}$ & Assessors & $\begin{array}{c}\text { Intervention group } \\
\text { (CBT-TAU) reported } \\
\text { higher HADS anxiety } \\
\text { scale }\end{array}$ & $1.56 \%$ & NFP \\
\hline $\begin{array}{l}\text { Craske et al., 2011; } \\
\text { Wolitzky-Taylor } \\
\text { et al., } 2012[23,37] \\
\end{array}$ & $\begin{array}{c}\text { Adequate } \\
\text { Random number } \\
\text { generator }\end{array}$ & $\begin{array}{l}\text { Opaque } \\
\text { envelopes }\end{array}$ & Assessors & $\begin{array}{l}\text { No statistically } \\
\text { significant difference }\end{array}$ & $44.54 \%$ & NFP \\
\hline $\begin{array}{l}\text { Gaylord et al., } 2011 \\
{[12]}\end{array}$ & $\begin{array}{c}\text { Adequate } \\
\text { Computer- } \\
\text { generated } \\
\text { random numbers }\end{array}$ & NR & $\begin{array}{l}\text { Patients, data } \\
\text { collectors, and } \\
\text { managers }\end{array}$ & $\begin{array}{c}\text { No statistically } \\
\text { significant difference }\end{array}$ & $12 \%$ & NFP \\
\hline
\end{tabular}


TABLE 1: Continued.

\begin{tabular}{|c|c|c|c|c|c|c|}
\hline $\begin{array}{l}\text { Author, year } \\
\text { (reference) }\end{array}$ & $\begin{array}{c}\text { Randomization } \\
\text { method }\end{array}$ & $\begin{array}{c}\text { Allocation } \\
\text { concealment }\end{array}$ & Blinding & Baseline imbalance & $\begin{array}{c}\text { Lost to } \\
\text { Follow-up }\end{array}$ & Source of funding \\
\hline Labus et al., 2013 [30] & $\begin{array}{c}\text { Inadequate } \\
\text { Quasi- } \\
\text { randomized }\end{array}$ & No & No & $\begin{array}{l}\text { Intervention group } \\
\text { (psychoeducation } \\
\text { group) reported lower } \\
\text { GI symptom severity } \\
\text { score and higher } \\
\text { HADS anxiety score } \\
\text { and level of education }\end{array}$ & NR & $\begin{array}{c}\text { Includes FPO } \\
\text { GlaxoSmithKline }\end{array}$ \\
\hline
\end{tabular}

NR: not reported; GI: gastrointestinal; IBS: irritable bowel syndrome; NFP: not-for-profit organization; DSM: Diagnostic and Statistical Manual of Mental Disorders; RCC: routine clinical care; CBT: cognitive behavioral therapy; TAU: treatment as usual; HADS: Hospital Anxiety and Depression Scale; FPO: forprofit organization.

$\mathrm{SMD}=-0.282 \mathrm{SD}(95 \% \mathrm{CI}$ from -0.562 to -0.001$)$. There was strong evidence of heterogeneity $\left(I^{2}=56.16 \%\right.$ and $P=$ $0.025)$.

Six trials reported changes in diarrhea scales and constipation scales (Figures 5 and 6). Random-effects metaanalyses showed no statistically significant difference in the change of diarrhea scales with SMD $=-0.448$ SD $(95 \% \mathrm{CI}$ from -0.912 to 0.017 ) and constipation scales with $\mathrm{SMD}=$ -0.130 SD ( $95 \%$ CI from -0.484 to 0.224 ) between subjects who received psychological therapy $(n=200)$ and who received the control $(n=146)$. Strong evidence of heterogeneity was observed in both meta-analyses of the diarrhea scales $\left(I^{2}=70.25 \%\right.$ and $\left.P=0.005\right)$ and the constipation scales $\left(I^{2}=50.24 \%\right.$ and $\left.P=0.074\right)$.

3.5. Subgroup Analysis. There was no statistically significant interaction based on the type of treatment (CBT versus other forms of psychotherapy), based on the risk of bias, or based on whether the control arm received pharmacological treatment $(P>0.05$, Table 3$)$. There were insufficient data to conduct subgroup analyses based on whether a placebo was used in the control arm or based on whether patients received prior treatment.

\section{Discussion}

We conducted a systematic review and meta-analysis of randomized controlled trial evaluating the effects of psychological therapies such as cognitive-behavioral therapy (CBT) and mind-body therapy (MBT) on IBS patients' symptoms and quality of life.

4.1. Main Findings. Our search identified 15 trials evaluating a psychological therapy on a sample of IBS patients. We excluded trials of hypnotherapy, as three reviews have already examined its effect on IBS. Outcomes were evaluated using validated scoring scales. The body of evidence varied from small in measures of diarrhea (346 subjects) and constipation (346 subjects) to moderate for the composite IBS symptom severity scales (680 patients). The conducted meta-analyses demonstrated a statistically significant effect of psychological therapies on IBS-Quality of Life and composite IBS symptom severity scales with minimal heterogeneity. In contrast, psychological therapies had no statistically significant effect on diarrhea and constipation with evidence of heterogeneity observed. Psychological therapies had a statistically significant effect on abdominal pain; however, this inference was limited by heterogeneity. It should be noted that the studies assessing these secondary outcomes might not have been adequately powered to evaluate changes in symptoms, as they were either secondary outcomes or part of a composite scale. The pooled effect sizes ranged from $0.13 \mathrm{SD}$ to $0.62 \mathrm{SD}$.

The standardized difference in the means was used to express the effect size for each outcome in standard deviation unit as each outcome was assessed using different scales. According to Cohen, a difference of $0.2 \mathrm{SD}$ is considered a small difference, $0.5 \mathrm{SD}$ is considered moderate, and $0.8 \mathrm{SD}$ is considered large [57]. Norman found that a $0.5 \mathrm{SD}$ was the minimally clinically important difference (MCID) for changes in most of health-related quality of life for chronic diseases [58]. Studies were done to validate and define the MCID for the IBS-Quality of Life scale [51, 52]. The MCID was found to be 10 to 14 points which is equal to 0.5 to 0.7 standard deviation units [59]. In this meta-analysis, the psychological therapy increased the quality of life scales by 0.604 SD units (95\% CI from 0.440 to 0.768 ) compared to control. Using the above MCID this translates to a clinically meaningful improvement in quality of life.

When Francis et al. described the IBS-Severity Scoring System (IBS-SSS), they found that a change of 50 points was sufficient to detect clinical improvement [48]. This is equal to $0.6 \mathrm{SD}$ in most of the trials that used the IBS-SSS in this meta-analysis [12, 28, 33, 34]. The psychological interventions decreased the symptom severity scales by 0.618 SD (95\% CI from -0.853 to -0.383 ) compared to control in the current meta-analysis. This translates to a clinically meaningful change consistent with improvement in the IBS symptoms severity scales.

The meta-analysis of the abdominal pain showed a statistically significant difference. We were not able to find a study that established the MCID for abdominal pain scales in patients with IBS. The psychological therapies decreased the abdominal pain scales by 0.282 SD (95\% CI from -0.562 to -0.001) and by applying Cohen's assumption [57] above this translates to a small difference. Also, this statistically significant difference was limited by the presence of heterogeneity.

The quality of evidence according to the GRADE [60] approach for the primary outcomes was low and moderate 


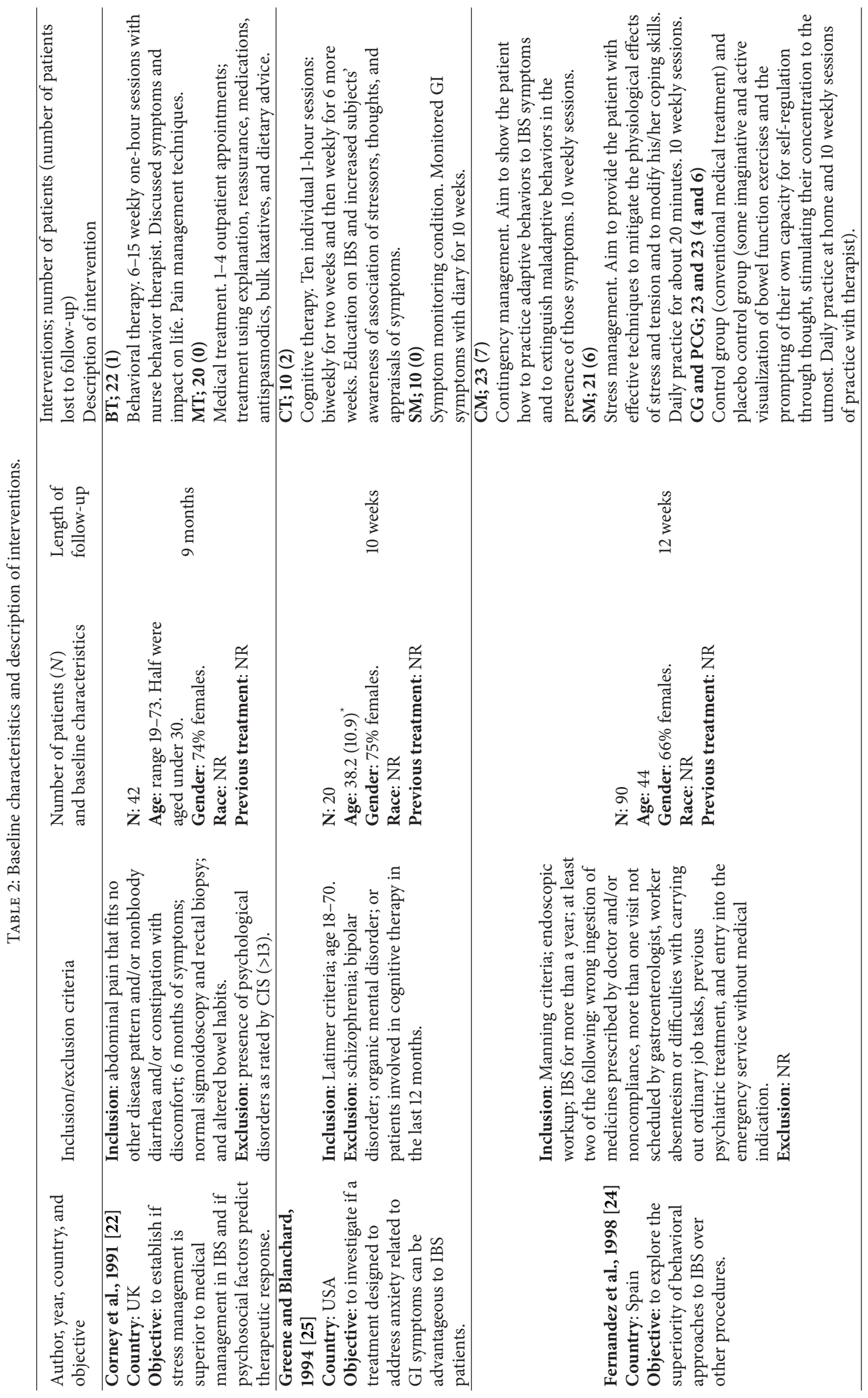




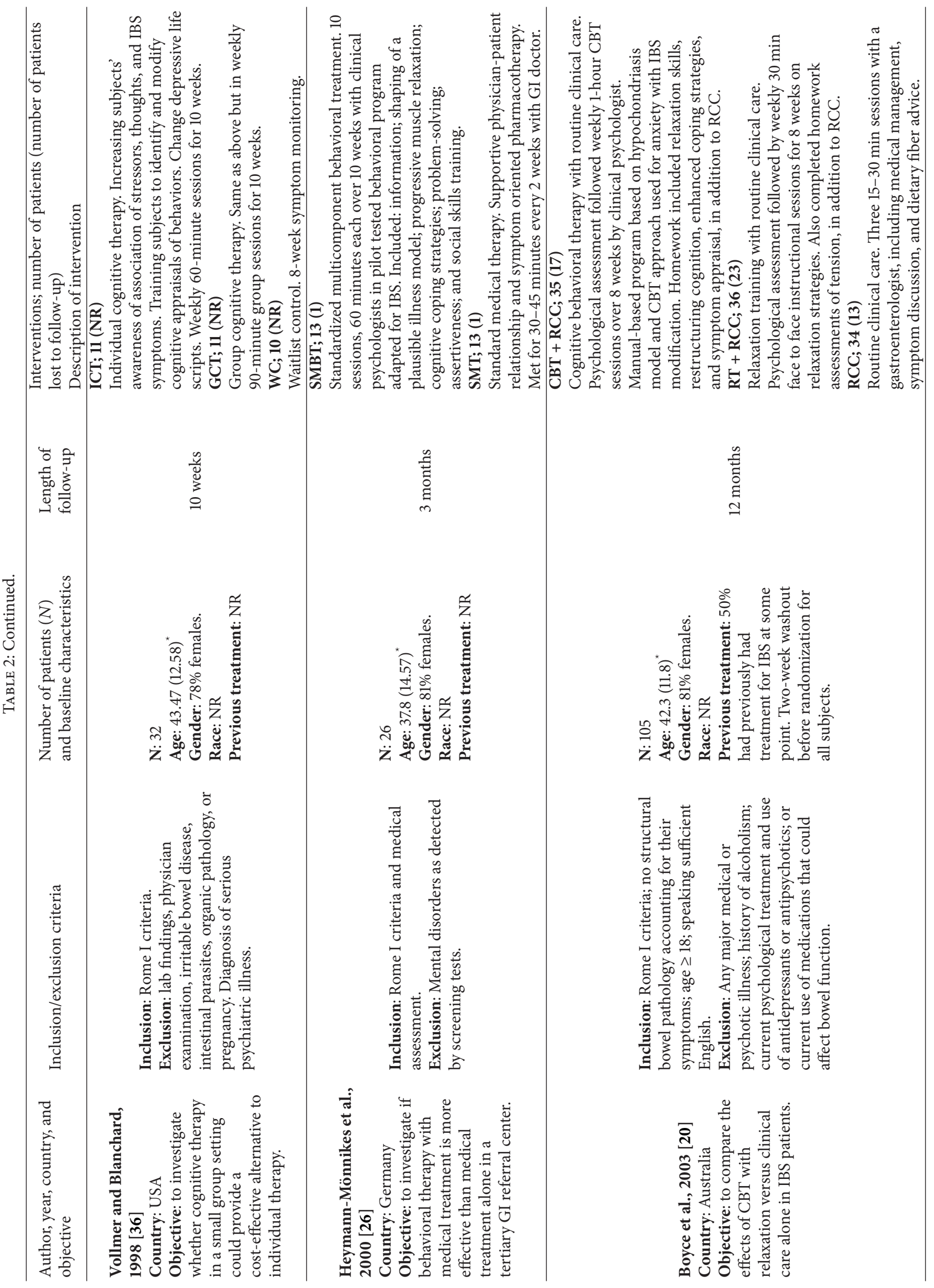




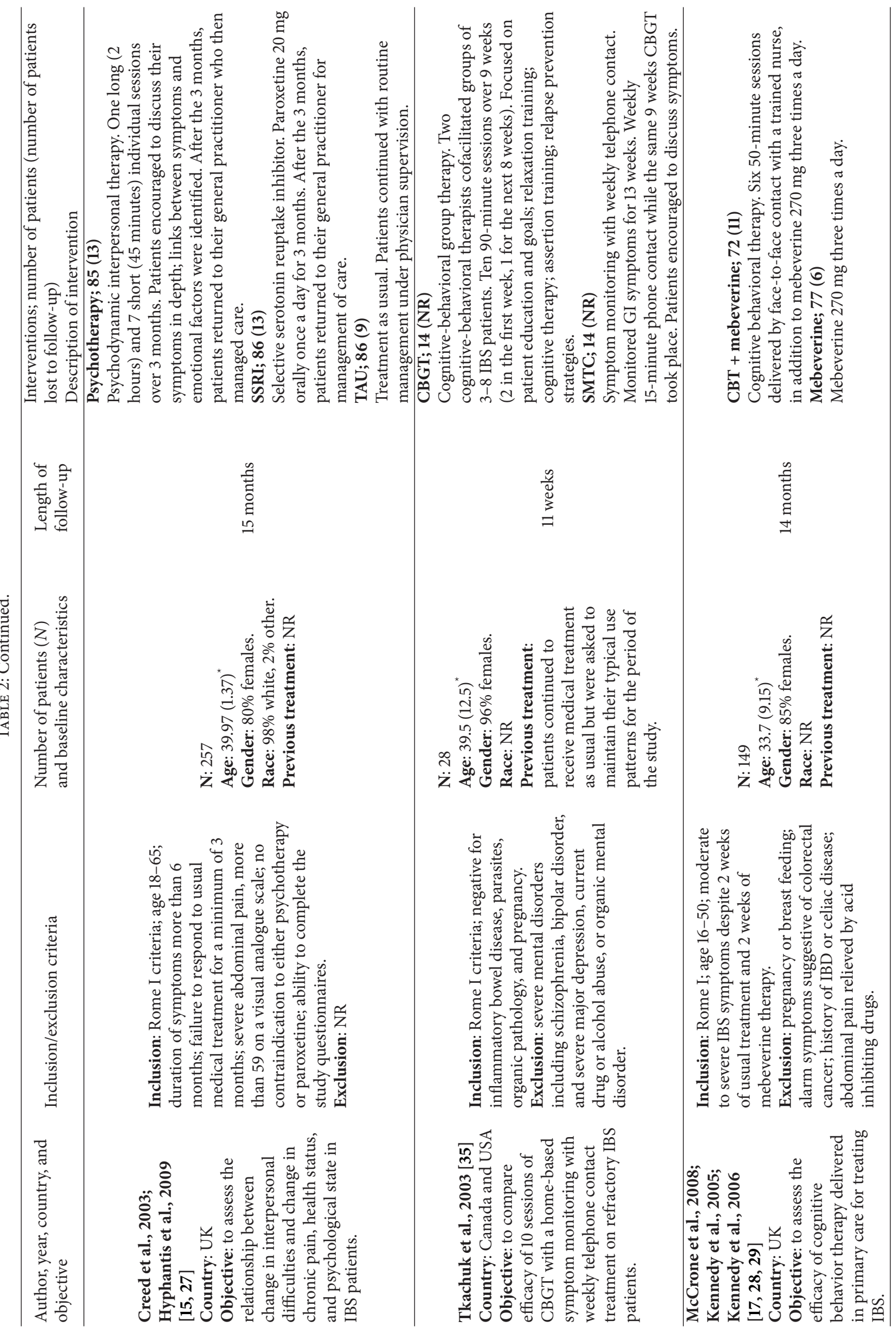




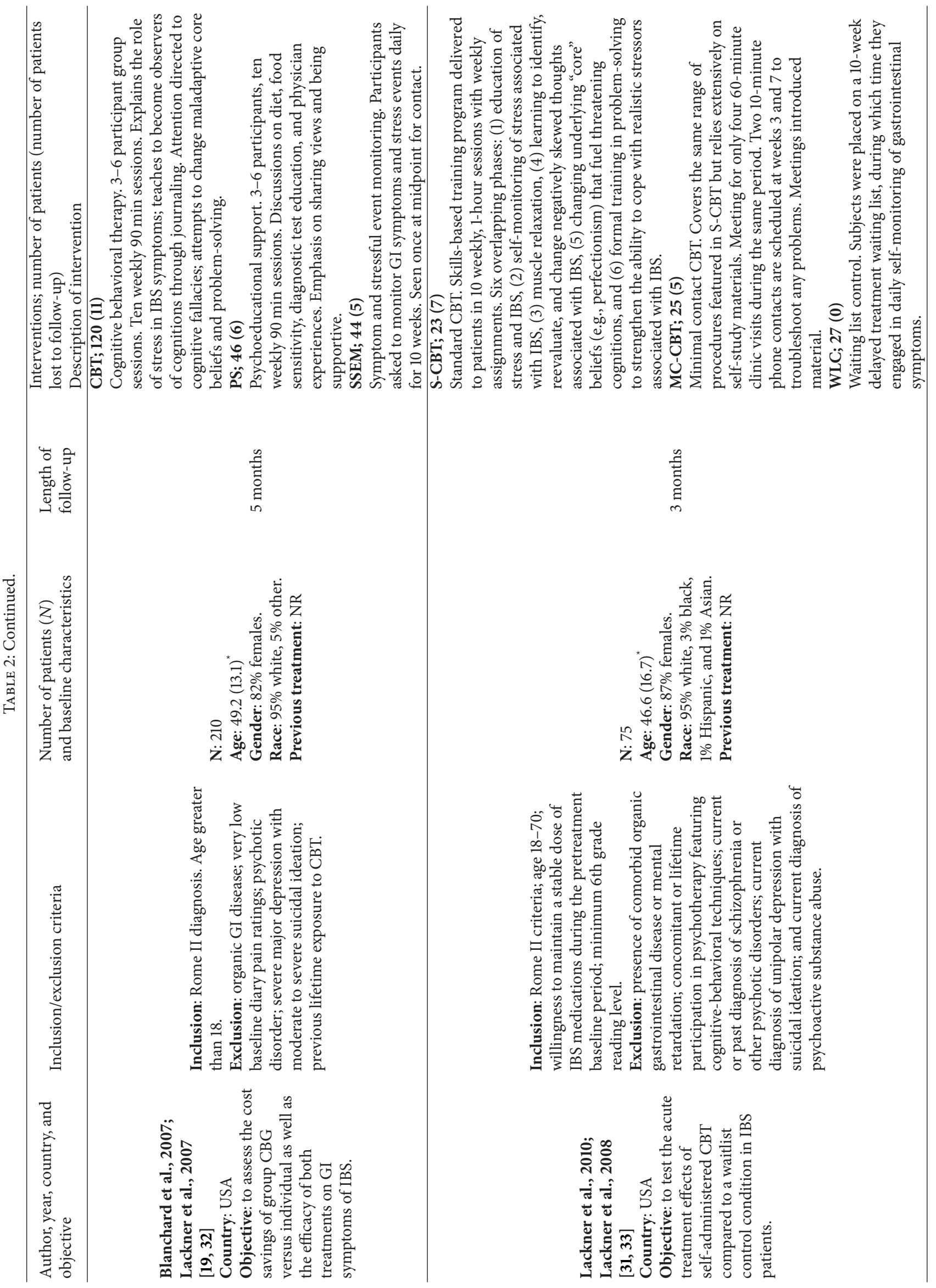




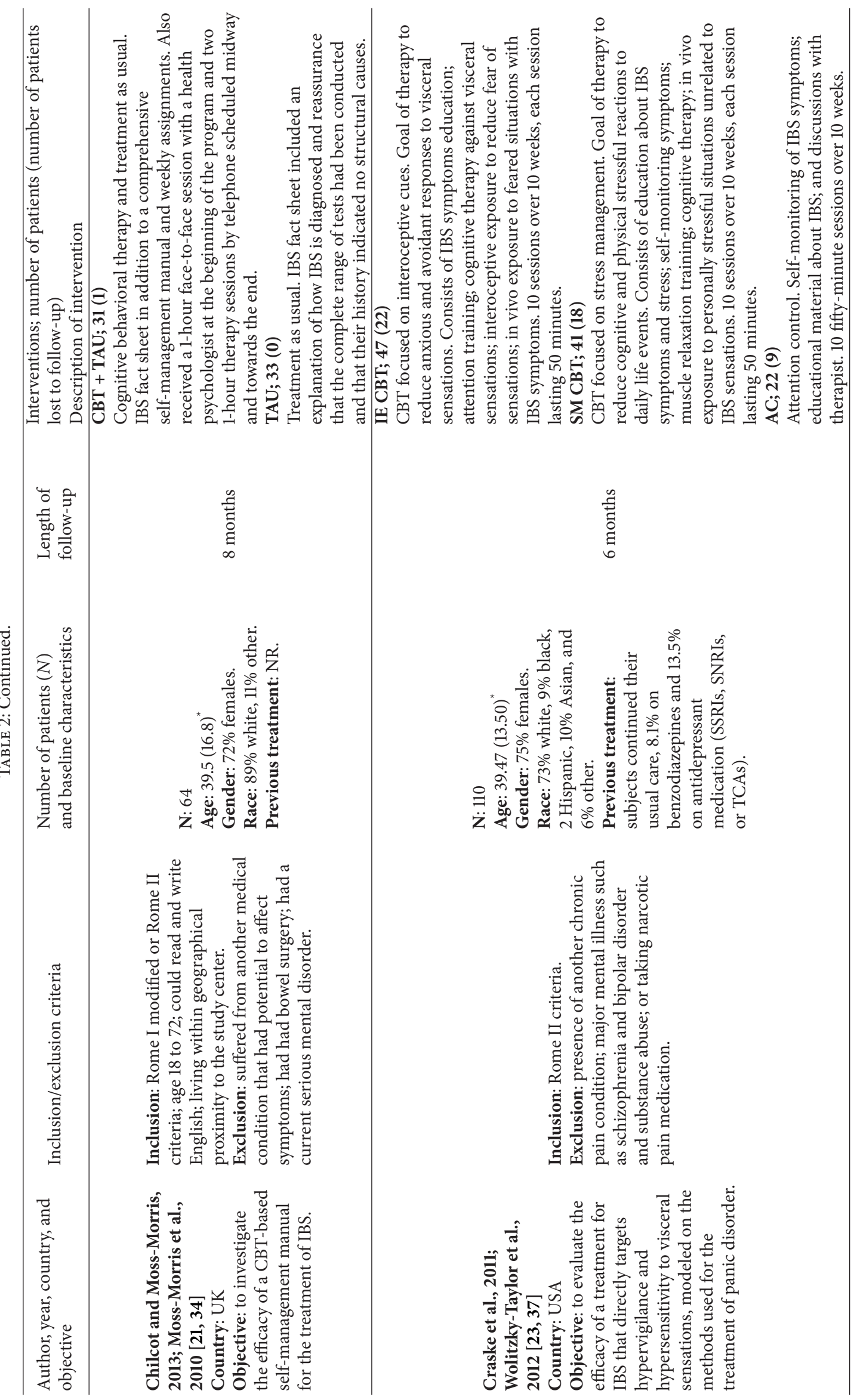




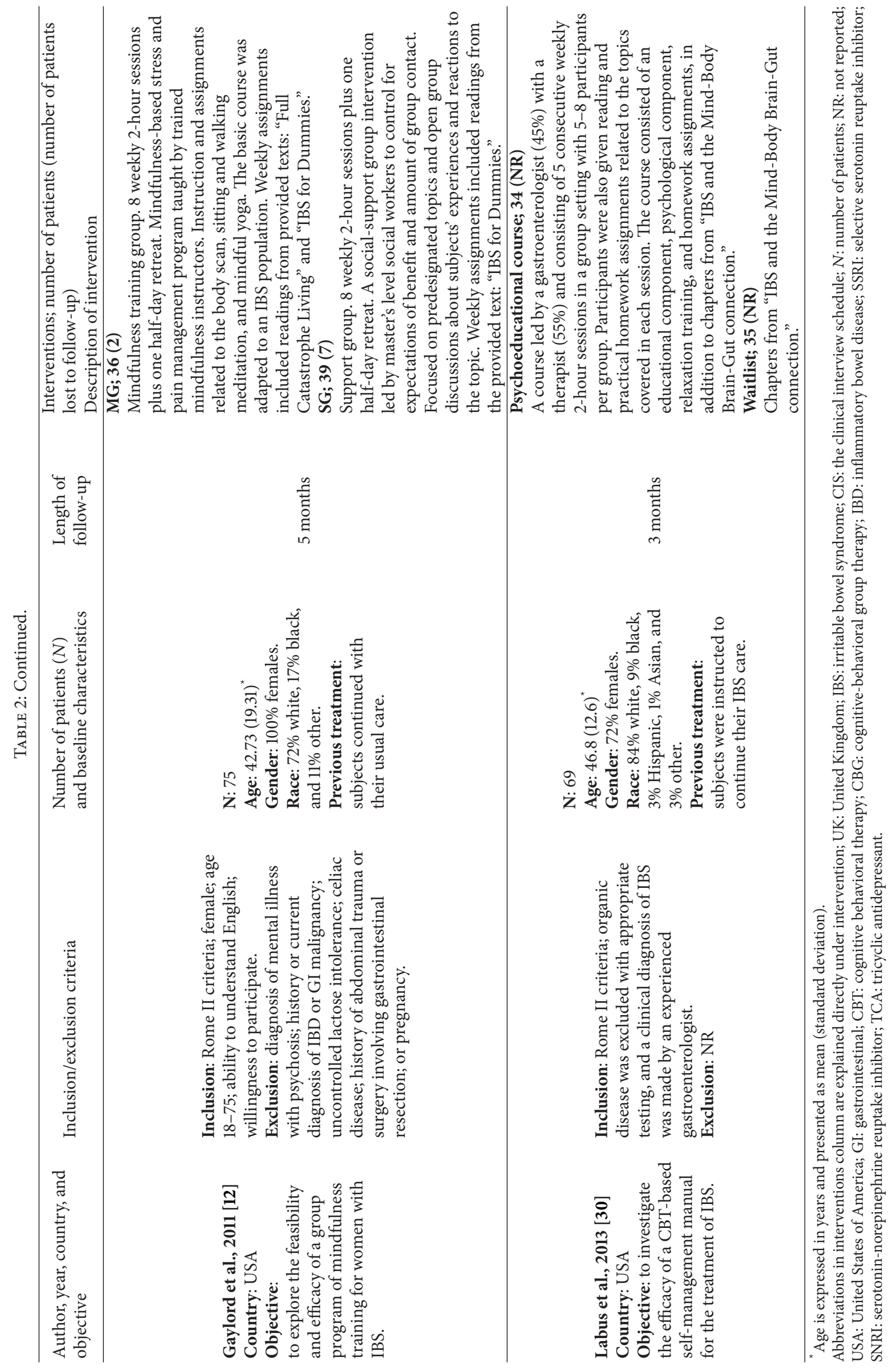




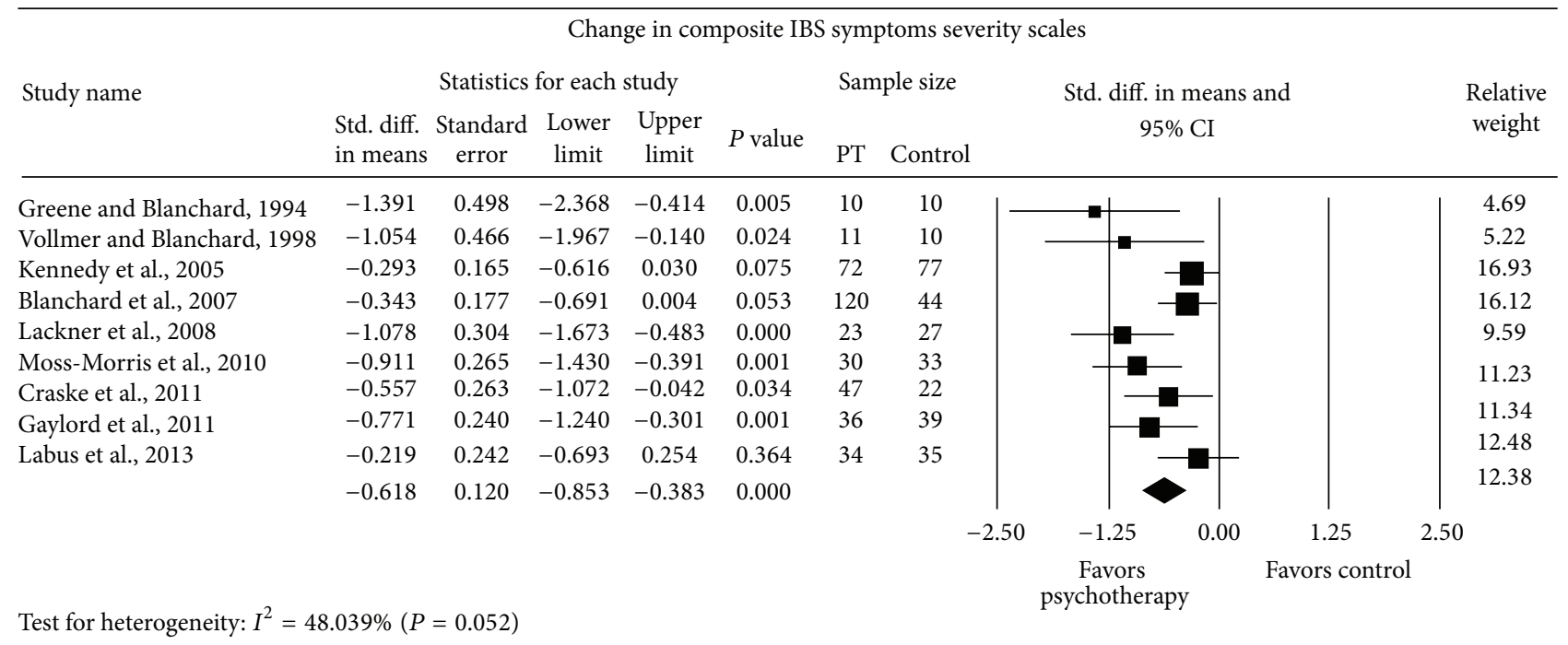

Meta-analysis

FIGURE 2: Forest plot for composite IBS symptoms severity scales in RCTs of psychotherapy (PT) versus control.

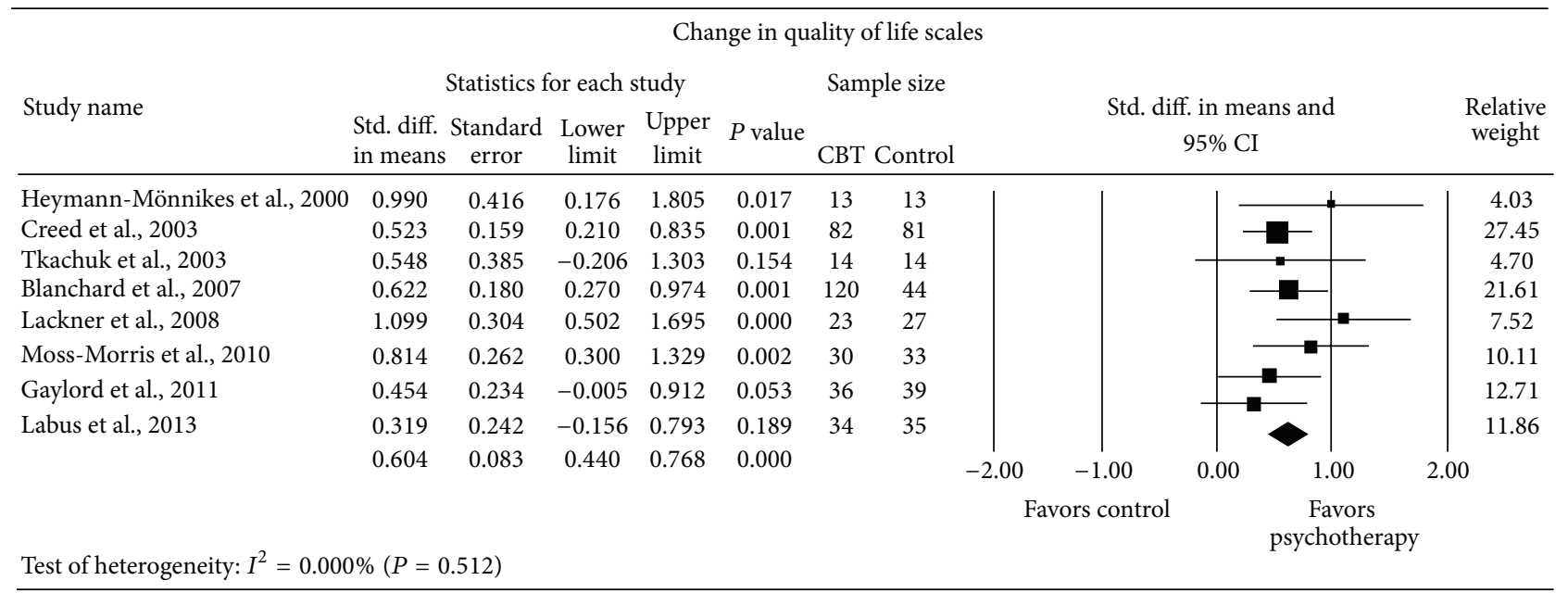

Meta-analysis

FIGURE 3: Forest plot for quality of life scales in RCTs of psychotherapy (PT) versus control.

for IBS symptom severity scale and IBS-Quality of Life, respectively, rated down for high and moderate risk of bias. The quality of evidence for secondary outcomes was very low, with downratings due to the overall high risk of bias, serious imprecision, and serious inconsistency in all of them.

4.2. Strengths and Limitations. By its nature IBS is a poorly understood, heterogeneous disease with varied clinical presentations and underlying etiologies. Despite this fact, all the trials evaluated used very similar protocols and criteria for defining their sample population of IBS patients, even if the criteria for IBS have evolved over the three decades from which these trials were conducted. Further strengths of this systematic review relate to the reviewers' measures taken to control bias. Some of these measures included study screening, quality evaluation, and data extraction in duplicate. The search strategy was comprehensive, extracting trials from multiple databases. To our knowledge, this is the first systematic review with accompanying meta-analysis to quantitatively measure the effects of psychological therapies, other than hypnotherapy, on gastrointestinal symptoms in patients with IBS.

There are many limitations in this review. The trials evaluated had many methodological limitations and were generally small. Although specific details on frequency and duration of the psychological interventions were given in the trials, the efficacy of psychological therapies such as cognitive-behavioral therapy can range considerably depending on the training and experience of the therapist. The therapy is also often modified in the presence of psychological 


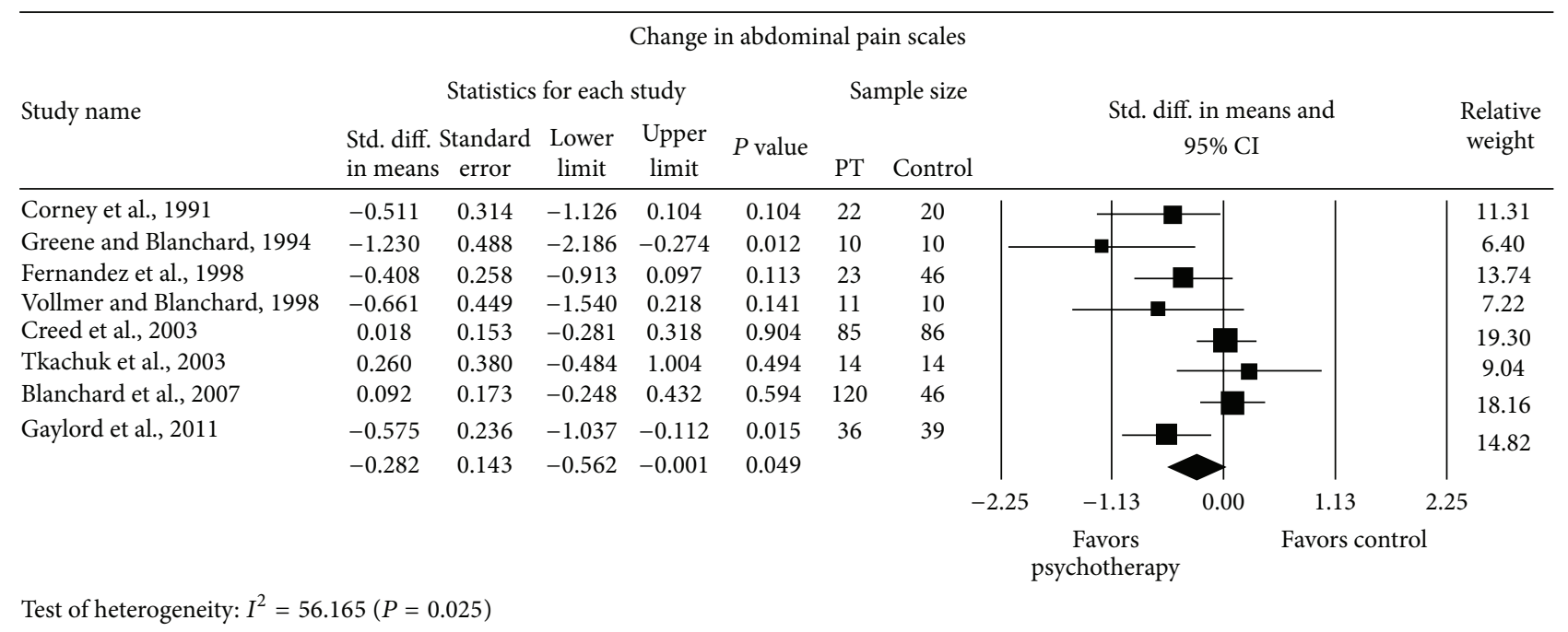

Meta-analysis

FIGURE 4: Forest plot for abdominal pain scales in RCTs of psychotherapy (PT) versus control.

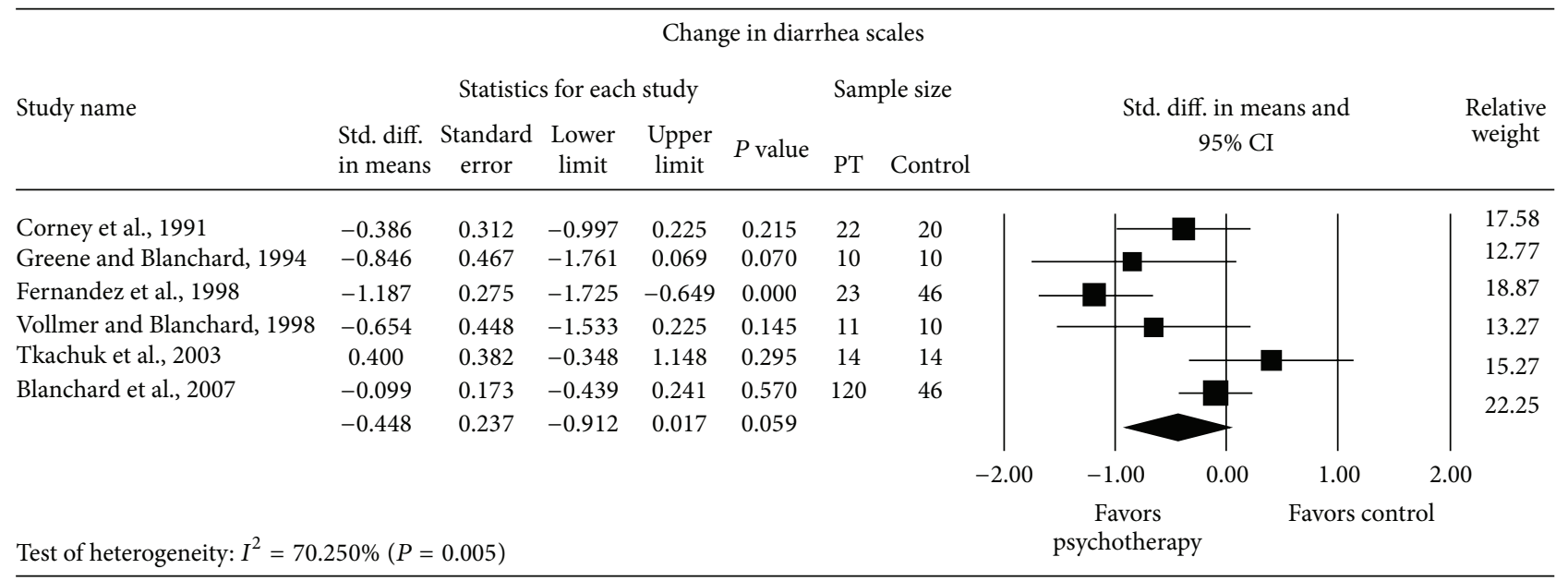

Meta-analysis

FIGURE 5: Forest plot for diarrhea scales in RCTs of psychotherapy (PT) versus control.

comorbidity, which is common in IBS patients. This can result in variability in the therapy given in the different trials. There was variability in the follow-up periods as well. Publication bias is likely in a field in which evidence consists of trials with small size. Further, the efficacy of CBT or MBT could be driven primarily by improvement in general feeling of wellbeing and lower stress, and not specific improvement in IBS pathophysiology.

Another limitation pertains to the heterogeneity of IBS itself. IBS is now recognized as including three main subtypes: IBS-diarrhea predominant, IBS-constipation predominant, and IBS-mixed type. Many patients also develop IBS as sequelae to gastrointestinal infection or what is termed postinfectious IBS. These subtypes may have varying etiologies underlying their pathophysiology. By failing to stratify results by these subtypes, we are unable to know if there would be differences in efficacy of psychological therapies between subtypes. This would have important practical implications for the clinical incorporation of psychological therapies in the treatment of IBS. In terms of the analysis, heterogeneity that remained unexplained despite subgroup analyses lowers the confidence in the meta-analytic estimates.

\section{Conclusion}

Psychological therapies such as cognitive-behavioral therapy and mind-body therapy may help to improve gastrointestinal symptoms and quality of life in IBS patients. Although statistical significance was found in IBS measures of quality 


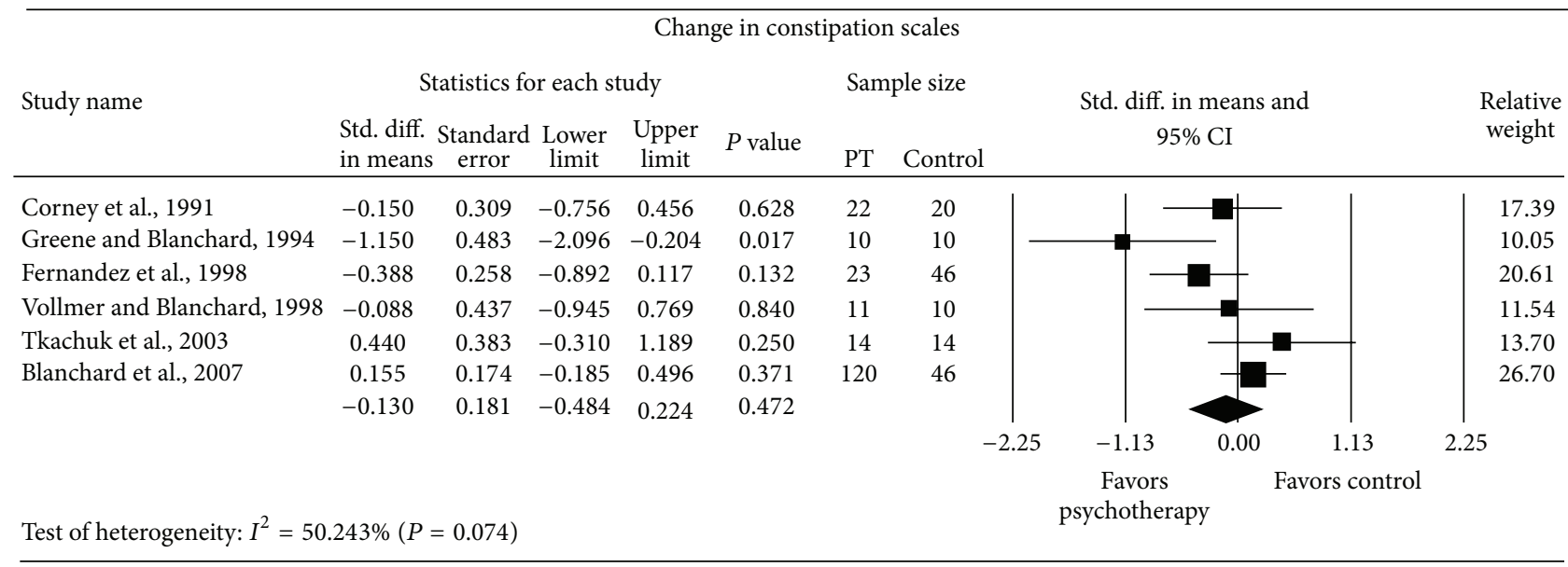

Meta-analysis

FIGURE 6: Forest plot for constipation scales in RCTs of psychotherapy (PT) versus control.

TABLE 3: Subgroup analysis.

\begin{tabular}{|c|c|c|c|c|}
\hline Subgroup & SMD & Lower limit & Upper limit & Interaction test \\
\hline \multicolumn{5}{|c|}{ Risk of bias: high versus low } \\
\hline \multicolumn{5}{|c|}{ Outcome: IBS composite symptoms severity scales } \\
\hline High & -0.56 & -1.07 & -0.04 & \multirow{2}{*}{$P$ value $=0.79$} \\
\hline Low & -0.64 & -0.90 & -0.37 & \\
\hline \multicolumn{5}{|c|}{ Intervention: CBT versus other forms of psychotherapy } \\
\hline \multicolumn{5}{|c|}{ Outcome: IBS composite symptoms severity scales } \\
\hline CBT & -0.57 & -0.86 & -0.28 & \multirow{2}{*}{$P$ value $=0.56$} \\
\hline Other & -0.74 & -1.21 & -0.26 & \\
\hline \multicolumn{5}{|c|}{ Outcome: quality of life scales } \\
\hline CBT & 0.74 & 0.49 & 0.99 & \multirow{2}{*}{$P$ value $=0.15$} \\
\hline Other & 0.50 & 0.28 & 0.72 & \\
\hline \multicolumn{5}{|c|}{ Control group: received medication versus no medication } \\
\hline \multicolumn{5}{|c|}{ Outcome: IBS composite symptoms severity scales } \\
\hline Yes & -0.67 & -1.01 & -0.33 & \multirow{2}{*}{$P$ value $=0.75$} \\
\hline No & -0.59 & -0.96 & -0.23 & \\
\hline \multicolumn{5}{|c|}{ Outcome: quality of life scales } \\
\hline Yes & 0.58 & 0.31 & 0.85 & \multirow{2}{*}{$P$ value $=0.80$} \\
\hline No & 0.62 & 0.39 & 0.86 & \\
\hline
\end{tabular}

SMD: standardized difference in means; IBS: irritable bowel syndrome; CBT: cognitive behavioral therapy.

of life and symptom severity, these results should be interpreted with caution as trials were generally of low quality. Future trials will require larger sample sizes, longer followup periods, and higher quality methodology to provide a definitive recommendation on the incorporation of psychological therapies in the treatment of IBS. However, despite these concerns, psychological therapies appear to be a safe intervention and could be a practical option for patients who fail standard medical therapy.

\section{Appendix}

\section{Actual Search Strategies}

\section{(1) Ovid}

Database(s). Embase 1988 to 2014 Week 05, Ovid MEDLINE(R) In-Process \& Other Non-Indexed Citations and Ovid MEDLINE(R) 1946 to Present, PsycINFO 1967 to January Week 3 2014, EBM Reviews-Cochrane Central Register 
of Controlled Trials December 2013, EBM Reviews-Cochrane Database of Systematic Reviews 2005 to December 2013.

Search Strategy (\#, Searches, Results)

(1) exp Irritable Bowel Syndrome/, 19426

(2) exp Irritable Colon/, 18648

(3) exp Colonic Diseases, Functional/, 23156

(4) ("Irritable bowel" "or "mucous colitis" or "irritable colon" or "functional colonic disease" or colonospasm " or "colon spasm" "or "mucomembraneous colitis" or "mucomembranous colitis" or "spastic colon" "or "spastic colitis" or "unstable colon" or "mucous colitides" or "colonic spasm"). mp., 27651

(5) or/1-4, 29503

(6) exp Psychotherapy/, 464651

(7) exp mind body therapy/, 76870

(8) exp mind-body therapies/, 76826

(9) exp Mindfulness/, 2940

(10) exp meditation/, 7934

(11) exp yoga/, 5954

(12) exp stress management/, 6155

(13) exp relaxation therapy/, 18867

(14) exp relaxation/, 31982

(15) exp hypnosis/, 25313

(16) exp anxiety management/, 385

(17) ((conditioning or psyc ${ }^{*}$ or cognit ${ }^{*}$ or behavior ${ }^{*}$ or stress or anxiety or breath ${ }^{*}$ or "insight-oriented talk" or "insight-oriented verbal" or "acceptance and commitment") adj3 (therap* or training or treat ${ }^{*}$ or technique $^{*}$ or procedure or manag ${ }^{*}$ or modifi ${ }^{*}$ or modify or technic or technics or rehab ${ }^{*}$ or restructur $\left.{ }^{*}\right)$ ). mp. [mp = ti, ab, sh, hw, tn, ot, dm, mf, dv, kw, nm, kf, px, rx, ui, tc, id, tm, tx, ct], 736491

(18) ((stress adj3 reduc $\left.{ }^{*}\right)$ or relaxation or meditat ${ }^{*}$ or hypnotherap " or hypnos" or biofeedback or "bio-feedback" or mindful " or psychotherap ${ }^{*}$ or logotherap ${ }^{*}$ or psychoanaly " or neurofeedback or "sensory feedback" or suggestion " or "behaviour contracting" or "consciousness raising" or yoga or yogic or "mind-body" or mindbody or imagery). mp., 872931

(19) or/6-18, 1552410

(20) 5 and 19, 3801

(21) exp controlled study/, 4359161

(22) exp randomized controlled trial/, 710055

(23) ((control\$ or randomized or randomised) adj2 (study or studies or trial or trials)). mp. [mp $=\mathrm{ti}, \mathrm{ab}, \mathrm{sh}, \mathrm{hw}$, tn, ot, dm, mf, dv, kw, nm, kf, px, rx, ui, tc, id, tm, tx, ct], 5642060

(24) meta analysis/, 127132
(25) meta-analys\$. mp., 220461

(26) exp "systematic review"/, 69727

(27) (systematic ${ }^{*}$ adj review\$). mp., 172449

(28) exp Cohort Studies/, 1569846

(29) exp longitudinal study/, 1000695

(30) exp retrospective study/, 825412

(31) exp prospective study/, 670821

(32) exp comparative study/, 2454433

(33) exp clinical trial/, 1711899

(34) exp cross-sectional study/, 283566

(35) crossover procedure/, 39737

(36) exp cross-over studies/, 97499

(37) multivariate analysis/, 186446

(38) ((clinical or comparative or cohort or longitudinal or retrospective or prospective or concurrent or "crosssectional" or crossover or "cross-over") adj (study or studies or survey or surveys or analysis or analyses or trial or trials)). mp., 7311926

(39) ("crossover procedure" or "cross-over procedure" or "multivariate analys"). mp. [mp $=\mathrm{ti}, \mathrm{ab}, \mathrm{sh}, \mathrm{hw}, \mathrm{tn}$, ot, dm, mf, dv, kw, nm, kf, px, rx, ui, tc, id, tm, tx, ct], 394850

(40) or/21-39, 11388240

(41) 20 and 40, 1798

(42) from 20 keep 2161-3109, 949

(43) limit 42 to (clinical trial, all or clinical trial, phase i or clinical trial, phase ii or clinical trial, phase iii or clinical trial, phase iv or clinical trial or comparative study or controlled clinical trial or evaluation studies or meta analysis or multicenter study or randomized controlled trial or systematic reviews) [Limit not valid in Embase, PsycINFO, CCTR, CDSR; records were retained], 253

(44) 41 or 43,1816

(45) limit 44 to (book or book series or editorial or erratum or letter or note or addresses or autobiography or bibliography or biography or comment or dictionary or directory or interactive tutorial or interview or lectures or legal cases or legislation or news or newspaper article or overall or patient education handout or periodical index or portraits or published erratum or video-audio media or webcasts) [Limit not valid in Embase, Ovid MEDLINE(R), Ovid MEDLINE(R) In-Process, PsycINFO, CCTR, CDSR; records were retained], 131

(46) 44 not 45, 1685

(47) from 20 keep 3567-3801, 235

(48) 46 or 47,1798

(49) 48 not (exp animals/ not exp humans/), 1626

(50) from 48 keep 1741-1798, 58 
(51) 49 or 50,1684

(52) limit 51 to $\mathrm{yr}=$ "1966-Current", 1684

(53) remove duplicates from 52, 1219

(2) Scopus

(1) TITLE-ABS-KEY ("Irritable bowel" " or "mucous colitis" or "irritable colon" or "functional colonic disease" or colonospasm" or "colon spasm" or "mucomembraneous colitis" or "mucomembranous colitis" or "spastic colon" or "spastic colitis" or "unstable colon" " or "mucous colitides" or "colonic $\operatorname{spasm}^{*}$ )

(2) TITLE-ABS-KEY ((conditioning W/3 therap ${ }^{*}$ ) or (conditioning $\mathrm{W} / 3$ training) or (conditioning $\mathrm{W} / 3$ treat $^{*}$ ) or (conditioning W/3 technique ${ }^{*}$ ) or (conditioning $\mathrm{W} / 3$ procedure ${ }^{*}$ ) or (conditioning $\mathrm{W} / 3$ manag $^{*}$ ) or (conditioning W/3 modifi ${ }^{*}$ ) or (conditioning $\mathrm{W} / 3$ modify) or (conditioning $\mathrm{W} / 3$ technic) or (conditioning $\mathrm{W} / 3$ technics) or (conditioning $\mathrm{W} / 3$ rehab $^{*}$ ) or (conditioning $\mathrm{W} / 3$ restructur $^{*}$ ) or (psyc ${ }^{*}$ $\mathrm{W} / 3$ therap $^{*}$ ) or (psyc $c^{*} \mathrm{~W} / 3$ training) or (psyc ${ }^{*} \mathrm{~W} / 3$ treat $\left.^{*}\right)$ or $\left(\right.$ psyc $^{*} \mathrm{~W} / 3$ technique $\left.{ }^{*}\right)$ or $\left(\right.$ psyc $^{*} \mathrm{~W} / 3$ procedure $^{*}$ ) or (psyc ${ }^{*} \mathrm{~W} / 3$ manag $\left.^{*}\right)$ or $\left(\right.$ psyc $^{*} \mathrm{~W} / 3$ modifi $^{*}$ ) or (psyc ${ }^{*} \mathrm{~W} / 3$ modify) or (psyc ${ }^{*} \mathrm{~W} / 3$ technic) or (psyc ${ }^{*} \mathrm{~W} / 3$ technics) or ( $\mathrm{psyc}^{*} \mathrm{~W} / 3 \mathrm{rehab}^{*}$ ) or $\left(\right.$ psyc $^{*} \mathrm{~W} / 3$ restructur $\left.{ }^{*}\right)$ or $\left(\right.$ cognit $^{*} \mathrm{~W} / 3$ therap $\left.^{*}\right)$ or (cognit ${ }^{*} \mathrm{~W} / 3$ training) or (cognit ${ }^{*} \mathrm{~W} / 3$ treat $^{*}$ ) or (cognit ${ }^{*} \mathrm{~W} / 3$ technique ${ }^{*}$ ) or (cognit ${ }^{*} \mathrm{~W} / 3$ procedure ${ }^{*}$ ) or $\left(\right.$ cognit $^{*} \mathrm{~W} / 3$ manag $\left.^{*}\right)$ or $\left(\right.$ cognit $^{*} \mathrm{~W} / 3$ modifi $\left.^{*}\right)$ or (cognit ${ }^{*} \mathrm{~W} / 3$ modify) or (cognit ${ }^{*} \mathrm{~W} / 3$ technic) or (cognit ${ }^{*} \mathrm{~W} / 3$ technics) or (cognit $\mathrm{W} / 3 \mathrm{rehab}^{*}$ ) or (cognit ${ }^{*} \mathrm{~W} / 3$ restructur $^{*}$ ) or (behavior ${ }^{*} \mathrm{~W} / 3$ therap $^{*}$ ) or (behavior ${ }^{*} \mathrm{~W} / 3$ training) or (behavior ${ }^{*} \mathrm{~W} / 3$ treat $^{*}$ ) or (behavior ${ }^{*} \mathrm{~W} / 3$ technique $^{*}$ ) or (behavior ${ }^{*}$ $\mathrm{W} / 3$ procedure ${ }^{*}$ ) or (behavior ${ }^{*} \mathrm{~W} / 3 \mathrm{manag}^{*}$ ) or (behavior $^{*} \mathrm{~W} / 3$ modifi $^{*}$ ) or (behavior ${ }^{*} \mathrm{~W} / 3 \mathrm{mod}-$ ify) or (behavior ${ }^{*} \mathrm{~W} / 3$ technic) or (behavior ${ }^{*} \mathrm{~W} / 3$ technics) or (behavior ${ }^{*} \mathrm{~W} / 3$ rehab $^{*}$ ) or (behavior ${ }^{*}$ $\mathrm{W} / 3$ restructur $^{*}$ ) or (stress $\mathrm{W} / 3$ therap $^{*}$ ) or (stress $\mathrm{W} / 3$ training) or (stress $\mathrm{W} / 3$ treat $^{*}$ ) or (stress $\mathrm{W} / 3$ technique $^{*}$ ) or (stress $\mathrm{W} / 3$ procedure ${ }^{*}$ ) or (stress $\mathrm{W} / 3$ manag $^{*}$ ) or (stress W/3 modifi ${ }^{*}$ ) or (stress W/3 modify) or (stress W/3 technic) or (stress W/3 technics) or (stress $\mathrm{W} / 3 \mathrm{rehab}^{*}$ ) or (stress $\mathrm{W} / 3$ restructur $^{*}$ ) or (anxiety $\mathrm{W} / 3$ therap $^{*}$ ) or (anxiety $\mathrm{W} / 3$ training) or (anxiety W/3 treat $^{*}$ ) or (anxiety W/3 technique ${ }^{*}$ ) or (anxiety W/3 procedure ${ }^{*}$ ) or (anxiety W/3 manag ${ }^{*}$ ) or (anxiety W/3 modifi ${ }^{*}$ ) or (anxiety W/3 modify) or (anxiety $\mathrm{W} / 3$ technic) or (anxiety W/3 technics) or (anxiety $\mathrm{W} / 3$ rehab $^{*}$ ) or (anxiety $\mathrm{W} / 3$ restructur $^{*}$ ) or (breath $^{*} \mathrm{~W} / 3$ therap $^{*}$ ) or (breath ${ }^{*} \mathrm{~W} / 3$ training) or (breath $^{*} \mathrm{~W} / 3$ treat $^{*}$ ) or (breath ${ }^{*} \mathrm{~W} / 3$ technique ${ }^{*}$ ) or (breath $^{*} \mathrm{~W} / 3$ procedure ${ }^{*}$ ) or (breath ${ }^{*} \mathrm{~W} / 3$ manag $^{*}$ ) or (breath ${ }^{*} \mathrm{~W} / 3$ modifi $^{*}$ ) or (breath ${ }^{*} \mathrm{~W} / 3$ modify) or (breath $^{*} \mathrm{~W} / 3$ technic) or (breath ${ }^{*} \mathrm{~W} / 3$ technics) or (breath $^{*} \mathrm{~W} / 3$ rehab $^{*}$ ) or (breath ${ }^{*} \mathrm{~W} / 3$ restructur $^{*}$ ) or (("insight-oriented talk" or "insight-oriented verbal" or "acceptance and commitment”) W/3 (therap* or training or treat ${ }^{*}$ or technique ${ }^{*}$ or procedure ${ }^{*}$ or manag $^{*}$ or modifi ${ }^{*}$ or modify or technic or technics or rehab ${ }^{*}$ or restructur $\left.\left.{ }^{*}\right)\right)$ )

(3) TITLE-ABS-KEY ((stress W/3 reduc ${ }^{*}$ ) or relaxation or meditat ${ }^{*}$ or hypnotherap ${ }^{*}$ or hypnos ${ }^{*}$ or biofeedback or "bio-feedback" or mindful ${ }^{*}$ or psychotherap* or logotherap ${ }^{*}$ or psychoanaly ${ }^{*}$ or neurofeedback or "sensory feedback" or suggestion * or "behaviour contracting" or "consciousness raising" or yoga or yogic or "mind-body" or mindbody or imagery)

(4) TITLE-ABS-KEY ((meta W/1 analys $\left.{ }^{*}\right)$ OR (systematic $^{*} \mathrm{~W} / 2$ review $^{*}$ ) OR (control ${ }^{*} \mathrm{~W} / 2$ stud $^{*}$ ) OR (control ${ }^{*} \mathrm{~W} / 2$ trial $^{*}$ ) OR (randomized ${ }^{*} \mathrm{~W} / 2$ stud $^{*}$ ) OR (randomized ${ }^{*} \mathrm{~W} / 2$ triall $^{*}$ ) OR (randomised W/2 stud $^{*}$ ) OR (randomised W/2 trial ${ }^{*}$ ) or "comparative stud" " OR "comparative survey" OR "comparative analys" " OR "cohort stud" OR "cohort survey" OR "cohort analys" "OR "longitudinal stud" " OR "longitudinal survey" ${ }^{*}$ OR "longitudinal analys" " OR "retrospective stud" "OR "retrospective survey" ${ }^{*}$ " OR "retrospective analys" or "prospective stud" "OR "prospective survey" OR "prospective analys" or "concurrent stud" "OR "concurrent survey " OR "concurrent analys " " or "clinical stud " OR "clinical trial " " or "cross-sectional stud" " or "cross-sectional analys " or "cross-over stud" " or "cross-over analys" " or "crossover procedure" or "crossover stud" or "crossover analys" " or "crossover procedure" or "multivariate analys ")

(5) PUBYEAR > 1965

(6) 1 and (2 or 3$)$ and 4 and 5

(7) $\operatorname{PMID}\left(0^{*}\right) \mathrm{OR} \operatorname{PMID}\left(1^{*}\right) \mathrm{OR} \operatorname{PMID}\left(2^{*}\right) \operatorname{OR} \operatorname{PMID}\left(3^{*}\right)$ OR PMID $\left(4^{*}\right)$ OR $\operatorname{PMID}\left(5^{*}\right)$ OR $\operatorname{PMID}\left(6^{*}\right)$ OR $\operatorname{PMID}\left(7^{*}\right)$ OR PMID $\left(8^{*}\right)$ OR $\operatorname{PMID}\left(9^{*}\right)$

(8) 6 and not 7

(9) DOCTYPE(le) OR DOCTYPE(ed) OR DOCTYPE(bk) OR DOCTYPE(er) OR DOCTYPE(no) OR DOCTYPE(sh)

(10) 8 and not 9.

\section{Conflict of Interests}

The authors declare that there is no conflict of interests regarding the publication of the paper.

\section{Authors' Contribution}

Study concept and design was made by Osama Altayar and Varun Sharma. Acquisition of data was carried out by Osama 
Altayar, Varun Sharma, and Larry J. Prokop. Analysis and interpretation of data was done by Osama Altayar, Varun Sharma, and Mohammad H. Murad. Drafting of the paper was done by Osama Altayar and Varun Sharma. Critical revision of the paper for important intellectual content was by Amit Sood and Mohammad H. Murad. Statistical analysis was carried out by Osama Altayar and Mohammad H. Murad. Osama Altayar, Varun Sharma, and Larry Prokop were responsible for administrative, technical, or material support. Study supervision was held by Varun Sharma and Mohammad Hassan Murad. Osama Altayar and Varun Sharma have equally contributed to this work.

\section{References}

[1] Y. A. Saito, P. Schoenfeld, and G. R. Locke III, "The epidemiology of irritable bowel syndrome in North America: a systematic review," The American Journal of Gastroenterology, vol. 97, no. 8, pp. 1910-1915, 2002.

[2] E. A. Mayer and K. Tillisch, "The brain-gut axis in abdominal pain syndromes," Annual Review of Medicine, vol. 62, pp. 381396, 2011.

[3] A. H. Böhmelt, U. M. Nater, S. Franke, D. H. Hellhammer, and U. Ehlert, "Basal and stimulated hypothalamic-pituitaryadrenal axis activity in patients with functional gastrointestinal disorders and healthy controls," Psychosomatic Medicine, vol. 67, no. 2, pp. 288-294, 2005.

[4] K. C. Cain, M. E. Jarrett, R. L. Burr, V. L. Hertig, and M. M. Heitkemper, "Heart rate variability is related to pain severity and predominant bowel pattern in women with irritable bowel syndrome," Neurogastroenterology \& Motility, vol. 19, no. 2, pp. 110-118, 2007.

[5] L. Z. FitzGerald, P. Kehoe, and K. Sinha, "Hypothalamicpituitary-adrenal axis dysregulation in women with irritable bowel syndrome in response to acute physical Stress," Western Journal of Nursing Research, vol. 31, no. 7, pp. 818-836, 2009.

[6] M. Heitkemper, R. L. Burr, M. Jarrett, V. Hertig, M. K. Lustyk, and E. F. Bond, "Evidence for autonomic nervous system imbalance in women with irritable bowel syndrome," Digestive Diseases and Sciences, vol. 43, no. 9, pp. 2093-2098, 1998.

[7] P. C. Konturek, T. Brzozowski, and S. J. Konturek, "Stress and the gut: pathophysiology, clinical consequences, diagnostic approach and treatment options," Journal of Physiology and Pharmacology, vol. 62, no. 6, pp. 591-599, 2011.

[8] A. Gholamrezaei, S. K. Ardestani, and M. H. Emami, "Where does hypnotherapy stand in the management of irritable bowel syndrome? A systematic review," Journal of Alternative and Complementary Medicine, vol. 12, no. 6, pp. 517-527, 2006.

[9] A. N. Webb, R. H. Kukuruzovic, A. G. Catto-Smith, and S. M. Sawyer, "Hypnotherapy for treatment of irritable bowel syndrome," Cochrane Database of Systematic Reviews, no. 4, Article ID CD005110, 2007.

[10] S. Wilson, T. Maddison, L. Roberts, S. Greenfield, and S. Singh, "Systematic review: the effectiveness of hypnotherapy in the management of irritable bowel syndrome," Alimentary Pharmacology \& Therapeutics, vol. 24, no. 5, pp. 769-780, 2006.

[11] D. A. Drossman, B. B. Toner, W. E. Whitehead et al., "Cognitivebehavioral therapy versus education and desipramine versus placebo for moderate to severe functional bowel disorders," Gastroenterology, vol. 125, no. 1, pp. 19-31, 2003.
[12] S. A. Gaylord, O. S. Palsson, E. L. Garland et al., "Mindfulness training reduces the severity of irritable bowel syndrome in women: results of a randomized controlled trial," The American Journal of Gastroenterology, vol. 106, no. 9, pp. 1678-1688, 2011.

[13] B. D. Naliboff, M. P. Fresé, and L. Rapgay, "Mind/body psychological treatments for irritable bowel syndrome," EvidenceBased Complementary and Alternative Medicine, vol. 5, no. 1, pp. 41-50, 2008.

[14] E. Andersson, B. Ljátsson, F. Smit et al., "Cost-effectiveness of internet-based cognitive behavior therapy for irritable bowel syndrome: results from a randomized controlled trial," $B M C$ Public Health, vol. 11, article 215, 2011.

[15] F. Creed, L. Fernandes, E. Guthrie et al., “The cost-effectiveness of psychotherapy and paroxetine for severe irritable bowel syndrome," Gastroenterology, vol. 124, no. 2, pp. 303-317, 2003.

[16] B. Ljótsson, G. Andersson, E. Andersson et al., "Acceptability, effectiveness, and cost-effectiveness of internet-based exposure treatment for irritable bowel syndrome in a clinical sample: a randomized controlled trial," BMC Gastroenterology, vol. 11, article 110, 2011.

[17] P. McCrone, M. Knapp, T. Kennedy et al., "Cost-effectiveness of cognitive behaviour therapy in addition to mebeverine for irritable bowel syndrome," European Journal of Gastroenterology \& Hepatology, vol. 20, no. 4, pp. 255-263, 2008.

[18] A. Liberati, D. G. Altman, J. Tetzlaff et al., "The PRISMA statement for reporting systematic reviews and meta-analyses of studies that evaluate health care interventions: explanation and elaboration," Journal of Clinical Epidemiology, vol. 62, no. 10, pp. el-e34, 2009.

[19] E. B. Blanchard, J. M. Lackner, K. Sanders et al., "A controlled evaluation of group cognitive therapy in the treatment of irritable bowel syndrome," Behaviour Research \& Therapy, vol. 45, no. 4, pp. 633-648, 2007.

[20] P. M. Boyce, N. J. Talley, B. Balaam, N. A. Koloski, and G. Truman, "A randomized controlled trial of cognitive behavior therapy, relaxation training, and routine clinical care for the irritable bowel syndrome," The American Journal of Gastroenterology, vol. 98, no. 10, pp. 2209-2218, 2003.

[21] J. Chilcot and R. Moss-Morris, "Changes in illness-related cognitions rather than distress mediate improvements in irritable bowel syndrome (IBS) symptoms and disability following a brief cognitive behavioural therapy intervention," Behaviour Research \& Therapy, vol. 51, no. 10, pp. 690-695, 2013.

[22] R. H. Corney, R. Stanton, R. Newell, A. Clare, and P. Fairclough, "Behavioural psychotherapy in the treatment of irritable bowel syndrome," Journal of Psychosomatic Research, vol. 35, no. 4-5, pp. 461-469, 1991.

[23] M. G. Craske, K. B. Wolitzky-Taylor, J. Labus et al., "A cognitivebehavioral treatment for irritable bowel syndrome using interoceptive exposure to visceral sensations," Behaviour Research \& Therapy, vol. 49, no. 6-7, pp. 413-421, 2011.

[24] C. Fernandez, M. Ferez, I. Amigo et al., "Stress and contingency management in the treatment of irritable bowel syndrome," Stress Medicine, vol. 14, no. 1, pp. 31-42, 1998.

[25] B. Greene and E. B. Blanchard, "Cognitive therapy for irritable bowel syndrome," Journal of Consulting and Clinical Psychology, vol. 62 , no. 3, pp. 576-582, 1994.

[26] I. Heymann-Mönnikes, R. Arnold, I. Florin, C. Herda, S. Melfsen, and H. Mönnikes, "The combination of medical treatment plus multicomponent behavioral therapy is superior to medical treatment alone in the therapy of irritable bowel 
syndrome," The American Journal of Gastroenterology, vol. 95, no. 4, pp. 981-994, 2000.

[27] T. Hyphantis, E. Guthrie, B. Tomenson, and F. Creed, "Psychodynamic interpersonal therapy and improvement in interpersonal difficulties in people with severe irritable bowel syndrome," Pain, vol. 145, no. 1-2, pp. 196-203, 2009.

[28] T. Kennedy, R. Jones, S. Darnley, P. Seed, S. Wessely, and T. Chalder, "Cognitive behaviour therapy in addition to antispasmodic treatment for irritable bowel syndrome in primary care: randomised controlled trial," British Medical Journal, vol. 331, no. 7514, pp. 435-437, 2005.

[29] T. M. Kennedy, T. Chalder, P. McCrone et al., "Cognitive behavioural therapy in addition to antispasmodic therapy for irritable bowel syndrome in primary care: randomised controlled trial," Health Technology Assessment, vol. 10, no. 19, pp. iii-iv, 2006.

[30] J. Labus, A. Gupta, H. K. Gill et al., "Randomised clinical trial: Symptoms of the irritable bowel syndrome are improved by a psycho-education group intervention," Alimentary Pharmacology and Therapeutics, vol. 37, no. 3, pp. 304-315, 2013.

[31] J. M. Lackner, G. D. Gudleski, L. Keefer, S. S. Krasner, C. Powell, and L. A. Katz, "Rapid response to cognitive behavior therapy predicts treatment outcome in patients with irritable bowel syndrome," Clinical Gastroenterology and Hepatology, vol. 8, no. 5, pp. 426-432, 2010.

[32] J. M. Lackner, J. Jaccard, S. S. Krasner, L. A. Katz, G. D. Gudleski, and E. B. Blanchard, "How does cognitive behavior therapy for irritable bowel syndrome work? A mediational analysis of a randomized clinical trial," Gastroenterology, vol. 133, no. 2, pp. 433-444, 2007.

[33] J. M. Lackner, J. Jaccard, S. S. Krasner, L. A. Katz, G. D. Gudleski, and K. Holroyd, "Self-administered cognitive behavior therapy for moderate to severe irritable bowel syndrome: clinical efficacy, tolerability, feasibility," Clinical Gastroenterology \& Hepatology, vol. 6, no. 8, pp. 899-906, 2008.

[34] R. Moss-Morris, L. McAlpine, L. P. Didsbury, and M. J. Spence, "A randomized controlled trial of a cognitive behavioural therapy-based self-management intervention for irritable bowel syndrome in primary care," Psychological Medicine, vol. 40, no. 1, pp. 85-94, 2010.

[35] G. A. Tkachuk, L. A. Graff, G. L. Martin, and C. N. Bernstein, "Randomized controlled trial of cognitive-behavioral group therapy for irritable bowel syndrome in a medical setting," Journal of Clinical Psychology in Medical Settings, vol. 10, no. 1, pp. 57-69, 2003.

[36] A. Vollmer and E. B. Blanchard, "Controlled comparison of individual versus group cognitive therapy for irritable bowel syndrome," Behavior Therapy, vol. 29, no. 1, pp. 19-33, 1998.

[37] K. Wolitzky-Taylor, M. G. Craske, J. S. Labus, E. A. Mayer, and B. D. Naliboff, "Visceral sensitivity as a mediator of outcome in the treatment of irritable bowel syndrome," Behaviour Research \& Therapy, vol. 50, no. 10, pp. 647-650, 2012.

[38] P. R. Latimer, Functional Gastrointestinal Disorders: A Behavioral Medicine Approach, Springer, New York, NY, USA, 1983.

[39] J. P. T. Higgins, D. G. Altman, P. C. Gøtzsche et al., "The Cochrane Collaboration's tool for assessing risk of bias in randomised trials," British Medical Journal, vol. 343, Article ID d5928, 2011.

[40] R. DerSimonian and N. Laird, "Meta-analysis in clinical trials," Controlled Clinical Trials, vol. 7, no. 3, pp. 177-188, 1986.
[41] J. P. Higgins, S. G. Thompson, J. J. Deeks, and D. G. Altman, "Measuring inconsistency in meta-analyses," British Medical Journal, vol. 327, no. 7414, pp. 557-560, 2003.

[42] J. P. A. Ioannidis and T. A. Trikalinos, "The appropriateness of asymmetry tests for publication bias in meta-analyses: a large survey," Canadian Medical Association Journal, vol. 176, no. 8, pp. 1091-1096, 2007.

[43] D. G. Altman and J. M. Bland, "Interaction revisited: the difference between two estimates," British Medical Journal, vol. 326, no. 7382, article 219, 2003.

[44] Biostat, "Comprehensive Meta-Analysis," version 2, Englewood, NJ, USA.

[45] A. P. Manning, W. G. Thompson, K. W. Heaton, and A. F. Morris, "Towards positive diagnosis of the irritable bowel," British Medical Journal, vol. 2, no. 6138, pp. 653-654, 1978.

[46] W. G. Thompson, F. Creed, D. A. Drossman, K. W. Heaton, and G. Mazzacca, "Functional bowel disease and functional abdominal pain," Gastroenterology International, vol. 5, no. 2, pp. 75-91, 1992.

[47] W. G. Thompson, G. F. Longstreth, D. A. Drossman, K. W. Heaton, E. J. Irvine, and S. A. Müller-Lissner, "Functional bowel disorders and functional abdominal pain," Gut, vol. 45, supplement 2, pp. II43-II47, 1999.

[48] C. Y. Francis, J. Morris, and P. J. Whorwell, “The irritable bowel severity scoring system: a simple method of monitoring irritable bowel syndrome and its progress," Alimentary Pharmacology \& Therapeutics, vol. 11, no. 2, pp. 395-402, 1997.

[49] E. B. Blanchard and S. P. Schwarz, "Clinically significant changes in behavioral medicine," Behavioral Assessment, vol. 10, no. 2, pp. 171-188, 1988.

[50] B. Spiegel, A. Strickland, B. D. Naliboff, E. A. Mayer, and L. Chang, "Predictors of patient-assessed illness severity in irritable bowel syndrome," The American Journal of Gastroenterology, vol. 103, no. 10, pp. 2536-2543, 2008.

[51] D. A. Drossman, D. L. Patrick, W. E. Whitehead et al., "Further validation of the IBS-QOL: a disease-specific quality-of-life questionnaire," The American Journal of Gastroenterology, vol. 95, no. 4, pp. 999-1007, 2000.

[52] D. L. Patrick, D. A. Drossman, I. O. Frederick, J. Dicesare, and K. L. Puder, "Quality of life in persons with irritable bowel syndrome: development and validation of a new measure," Digestive Diseases and Sciences, vol. 43, no. 2, pp. 400-411, 1998.

[53] J. E. Ware Jr. and C. D. Sherbourne, "The MOS 36-item shortform health survey (SF-36). I. Conceptual framework and item selection," Medical Care, vol. 30, no. 6, pp. 473-483, 1992.

[54] B. A. Hahn, L. J. Kirchdoerfer, S. Fullerton, and E. Mayer, "Evaluation of a new quality of life questionnaire for patients with irritable bowel syndrome," Alimentary Pharmacology and Therapeutics, vol. 11, no. 3, pp. 547-552, 1997.

[55] E. Eypasch, J. I. Williams, S. Wood-Dauphinee et al., "Gastrointestinal quality of life index: development, validation and application of a new instrument," British Journal of Surgery, vol. 82, no. 2, pp. 216-222, 1995.

[56] J. C. Mundt, I. M. Marks, M. K. Shear, and J. H. Greist, "The Work and Social Adjustment Scale: a simple measure of impairment in functioning," British Journal of Psychiatry, vol. 180, pp. 461-464, 2002.

[57] J. Cohen, Statistical Power Analysis for the Behavioral Sciences, Lawrence Erlbaum Associates, New York, NY, USA, 1988.

[58] G. R. Norman, J. A. Sloan, and K. W. Wyrwich, "Interpretation of changes in health-related quality of life: the remarkable 
universality of half a standard deviation," Medical Care, vol. 41, no. 5, pp. 582-592, 2003.

[59] D. Drossman, C. B. Morris, Y. Hu et al., "Characterization of health related quality of life (HRQOL) for patients with functional bowel disorder (FBD) and its response to treatment," The American Journal of Gastroenterology, vol. 102, no. 7, pp. 1442-1453, 2007.

[60] G. H. Guyatt, A. D. Oxman, H. J. Schünemann, P. Tugwell, and A. Knottnerus, "GRADE guidelines: a new series of articles in the Journal of Clinical Epidemiology," Journal of Clinical Epidemiology, vol. 64, no. 4, pp. 380-382, 2011. 


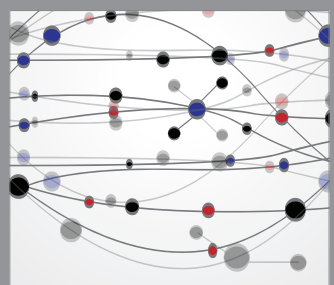

The Scientific World Journal
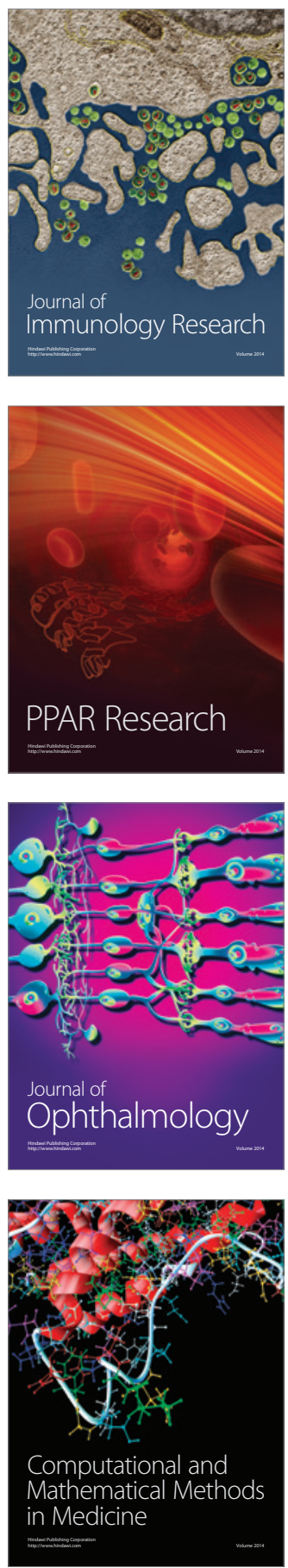

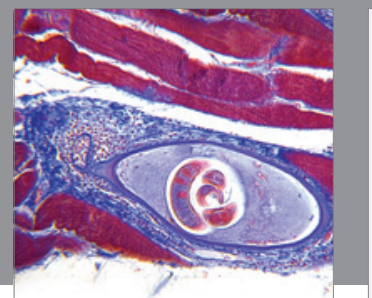

Gastroenterology

Research and Practice
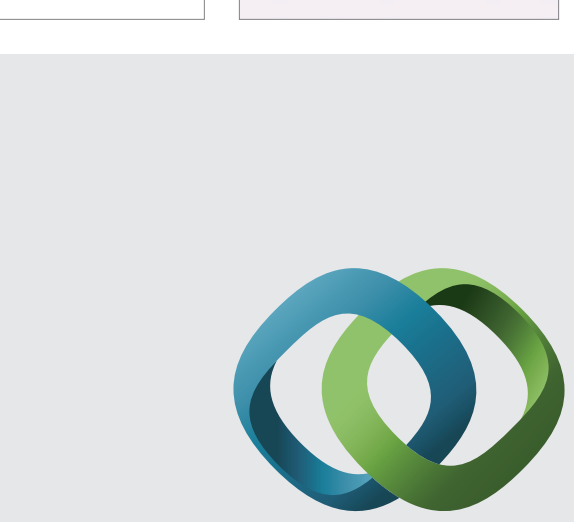

\section{Hindawi}

Submit your manuscripts at

http://www.hindawi.com
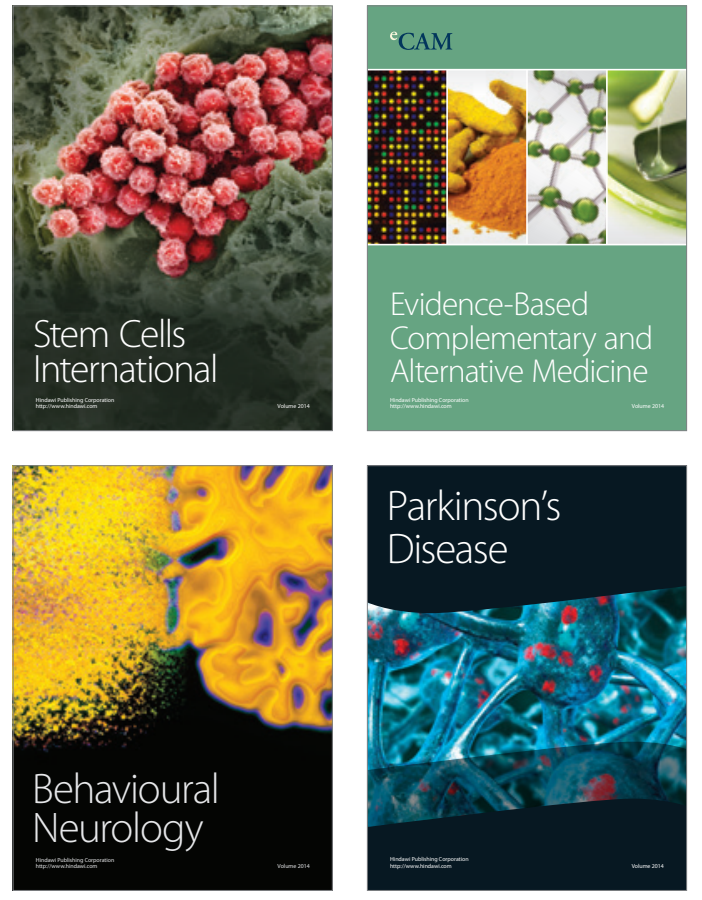
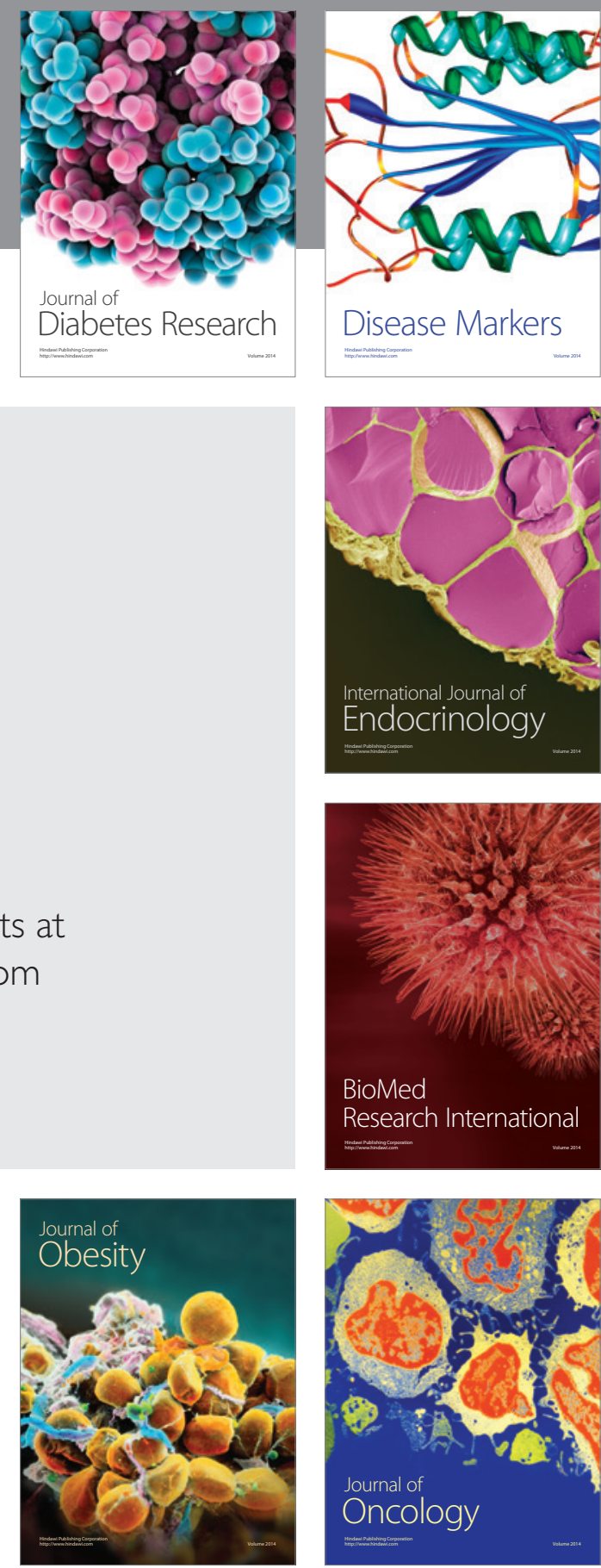

Disease Markers
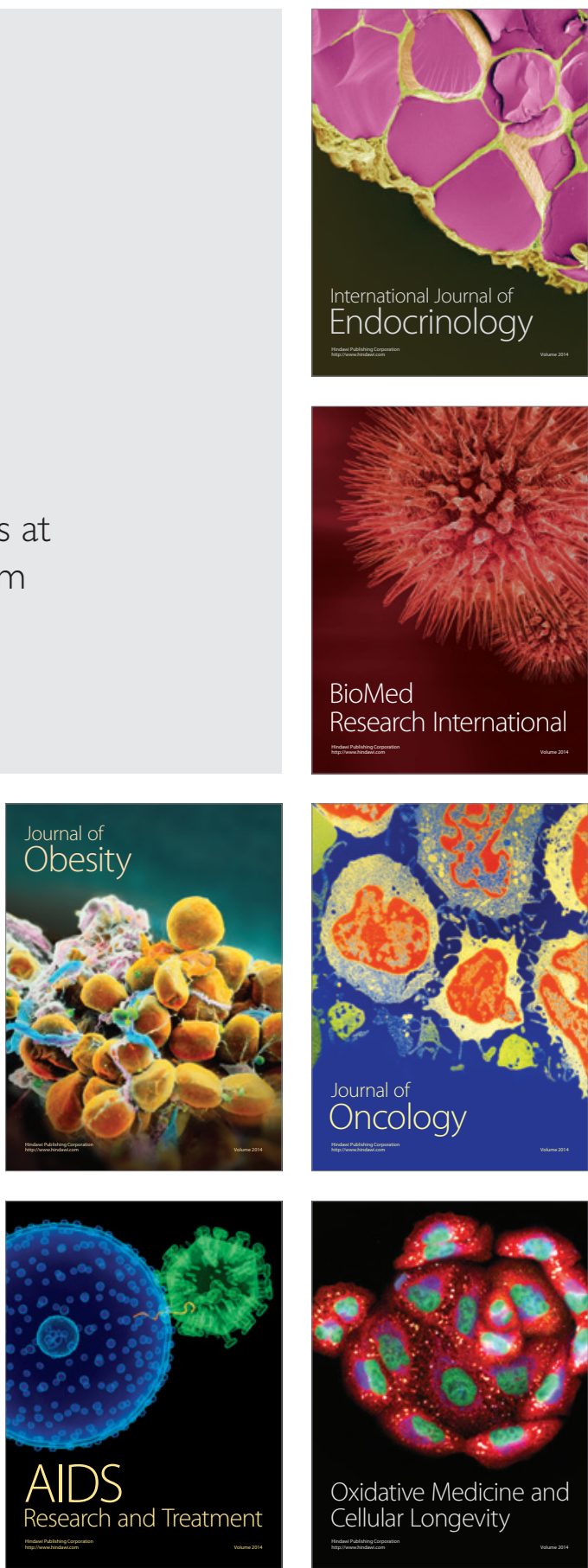